\title{
United We Stand: The Impact of Buying Groups on Retailer Productivity
}

In diverse industries, from grocery retailing to health care, retailers join buying groups to achieve better terms with suppliers. The authors track the buying group membership of Europe's largest grocery retailers over a 15-year period and evaluate why some buying groups are better than others in increasing retailer performance and why different members belonging to the same group do not always benefit equally from their membership. They find that, on average, buying groups indeed generate scale advantages for their members: group scale increases group members' productivity and sales and decreases their cost of goods sold. Still, bigger is not always better. Retailers benefit less from buying group scale when the group is more heterogeneous in terms of member size and when it extends its scope across too many markets. Moreover, the smaller a member is within the group and the more it overlaps with fellow members, the less it benefits.

Keywords: buying groups, retailing, alliances, channel relationships, retailer productivity

Online Supplement: http://dx.doi.org/10.1509/jm.14.0202

$\mathbf{P}$ urchasing through buying groups to obtain better terms with suppliers is becoming increasingly popular among retailers, manufacturers, and public sector organizations (Schotanus, Telgen, and De Boer 2008). A recent investigation by Spend Matters/Allianza Partners has revealed that no less than " $15-20 \%$ of the Fortune 1000 currently use buying consortiums" (Moore and Gray 2011). Buying groups (also known as buying consortia or group purchasing organizations) cross many industries, ranging from jewelry (e.g., Continental Buying Group, worth more than $\$ 1$ billion in retail sales) to hardware (e.g., ProGroup, representing $\$ 3$ billion in sales) or auto parts (e.g., Aftermarket Auto Parts Alliance, representing more than 50 auto parts distributors in the United States and abroad and billions of dollars in retail value). These groups have quickly become a major force in the supply chain. For example, in the U.S. health care products market, more than $80 \%$ of hospitals route $50 \%$ or more of their commodity-item and pharmaceutical spending through buying groups (Hu, Schwarz, and Uhan 2012).

In addition, grocery retailers have aggressively joined buying groups in an attempt to increase their performance (Dobson 2011; O'Shaughnessy 2014). A prominent exam-

Inge Geyskens is Professor of Marketing, Tilburg University (e-mail: I.Geyskens@tilburguniversity.edu). Katrijn Gielens is Associate Professor of Marketing, University of North Carolina at Chapel Hill (e-mail: katrijn gielens@unc.edu). Stefan Wuyts is Associate Professor of Marketing, Koç University, and Associate Professor of Marketing, Tilburg University (e-mail: swuyts@ku.edu.tr). The authors are indebted to the Netherlands Organization for Scientific Research (NWO) for financial assistance. Jan Heide served as area editor for this article. ple in the United States is Topco, which represents more than 50 member-owners across the country (including Harris Teeter, Save Mart, Wegmans, and Weiss), more than $\$ 120$ billion in sales, and thousands of stores. In Europe, buying groups such as AMS Sourcing, Coopernic, and EMD have become the most powerful participants in the market. Of the ten largest grocery buyers in Europe, five are buying groups rather than stand-alone retailers.

Despite being called "the new Zeitgeist" (Planet Retail 2014a) and "a development to watch" (O'Shaughnessy 2014), buying groups have received little attention in the academic literature. Although the marketing field has studied the increasing power of retailers over suppliers (e.g., Ailawadi 2001; Messinger and Narasimhan 2001), the buying group has not been the subject of systematic empirical inquiry. In the supply chain and operations management literature, a few studies have begun to investigate the potential success factors of buying groups, using case studies, interviews, surveys, and game-theoretic models. Nollet and Beaulieu (2005) report varying effects of pooled purchasing volumes on buy-in prices in health care purchasing and conclude that groups whose members have relatively homogeneous characteristics are desirable. Schotanus, Telgen, and De Boer (2010) also list uniformity among the group members as a potential success factor. Using a game-theoretic approach, Chen and Roma (2011) conclude that retailers may not always benefit from pooling their purchasing power, especially when they are heterogeneous in size and interests. Notably, Li (2012) finds that while buying groups often prefer members with similar preferences, group purchase may be particularly useful when buyers' markets are highly differentiated. Indeed, although similarity may help 
overcome differences in interest, similarity can also be an impediment because it stimulates upfront competition.

Business practice also reveals this discord with respect to the desirability of group diversity. For example, members of buying group IRTS cited differences in their portfolio of operations and their incompatibility in terms of overseas markets as the prime reasons for their group's dissolution in 2006 (Planet Retail 2006). In contrast, French retailer Système $U$, renowned for its supermarkets, recently indicated that it decided to join Auchan, a big-box specialist, because their different formats and geographical footprints represent strengths, as direct competition between the two parties is relatively limited (Planet Retail 2014b).

Taking these insights together, we conclude that a common understanding of the impact of group diversity on member performance has not yet been reached. Moreover, the extant literature on horizontal alliances has remained surprisingly mum with respect to the dimensions that underlie diversity. Retailers, therefore, have little to go on when deciding which buying group to join, how to shape a new group, or which candidate(s) to recruit to extend the group in which they participate. In this article, we aim to enhance marketing's understanding of the effect of buying group composition on retailer performance. The contribution of this study is twofold.

First, we provide an empirical test of the effect of buying group scale on member performance. Is bigger really better? A lack of data has been cited as the root cause of the scarcity of insight into the buying group phenomenon. Indeed, "there is very little credible information on ... buying groups within the public domain," presumably because "the groups themselves ... maintain a fairly low public profile" (IGD 2006, p. 63). Using a carefully assembled sample, we track the buying group membership of Europe's 130 largest grocery retailers over 15 years and test whether retailer performance is affected by buying group scale. Thus, we add to the empirical knowledge base on an issue in need of more research.

Second, we go beyond the "whether bigger is better" question and develop a contingency framework to examine "when bigger is better." Why are some buying groups better than others in translating aggregate scale into increased retailer performance? And why do different members belonging to the same buying group not always benefit equally from group membership? Retailer buying groups come in many forms and may display varied characteristics in terms of member size and market operations. Some buying groups represent similar-sized businesses operating in concert (e.g., Superunie), whereas others are made up of one large dominant member and several smaller members (e.g., Ahold is often described as "the 800-pound gorilla" in the AMS Sourcing group). Some groups remain strictly national in scope (e.g., Superunie only operates in the Netherlands), whereas others are truly multinational (e.g., the IRTS group had stores in 26 countries worldwide, including the United States, Mexico, Argentina, China, Bahrain, and Morocco). We test how the composition of a buying group in terms of (1) the size of its members and (2) its members' market operations affects the extent to which group members benefit from aggregation. We further argue that some firms experience superior membership benefits compared with others, even if they belong to the same group, and we test how the similarity of a retailer to its group peers affects that firm's capacity to benefit from the group.

We find that, on average, buying groups indeed generate scale advantages for their members. However, bigger is not always better. Retailers benefit less from buying group scale when the group is more diverse in terms of member size and when it extends its scope across too many markets. Moreover, the smaller a member is within the group and the more it overlaps with fellow members in terms of markets served, the less it will benefit. These results have important theoretical implications. In particular, our research illustrates the importance of distinguishing different types of member diversity because they exert different effects. In addition, our results contribute to a better understanding of horizontal alliances in demonstrating that partner diversity plays a different role in buying groups compared with other horizontal alliances.

\section{Background 1}

\section{Buying Groups}

Group activities. Buying groups aggregate the demand of several retailers to achieve better buying terms with suppliers than might be achieved through individual negotiation. For a retailer, the task of selecting suppliers that offer the best overall value proposition is daunting. With hundreds of potential suppliers to evaluate, the decision-making process can consume weeks of valuable time and often results in less-than-ideal outcomes. A buying group surveys all its members with regard to their experiences of dealing with a supplier and next negotiates with key suppliers that are vying for the group's business. No member is allowed to know the buying terms of any other member; this information is shared strictly with the group. After negotiating, the group draws up an umbrella contract. All members can buy products from the supplier under the terms of this contract. The umbrella contract covers "factory gate" prices only, leaving members free to decide whether to pay extra for transport or to make other arrangements. Members are similarly free to negotiate promotional activities separately with the supplier. Buying groups do not process orders, make payments, or carry out category planning on behalf of their members. Furthermore, buying groups rarely purchase the full range of goods sold by their members but, rather, aggregate demand for a more limited range.

1This section is based on information retrieved from (1) dedicated retail industry specialists (IGD and Planet Retail); (2) various buying group websites; (3) interviews by Dawson and Müller (2010) and ESM (2012) with the managing director of AMS Sourcing; (4) Ghisli, Lupe, and Da Silveira's (2014) interviews with buying groups, retailers, and industry experts in 13 countries; and (5) personal communication with three industry experts (the director of Strategic Initiatives from GfK Benelux, the director of the EFMI Business School [a knowledge center for the food sector], and a knowledgeable retail practitioner with substantial experience working with buying groups). 
Membership. Membership contracts are typically simple, with minimal stipulations. Buying groups regularly attract new members to increase their scale, and members are also free to leave as desired with virtually no penalties for withdrawing. As such, buying groups are in a continuous state of flux. Membership is not open: to join, a candidate must be approved by the existing members. Retailers do not join multiple groups concurrently for the same product line, although they may partake in groups focusing on different product lines (e.g., Intermarché is involved in Alidis/Agenor for grocery but in other groups for nongrocery categories). ${ }^{2}$

Ownership. Buying groups have their own legal and commercial identity, separate from that of their members. Buying group shares are owned by the members but are not necessarily commensurate to the members' purchases through the buying group. For example, although Rewe accounted for more than $40 \%$ of aggregate turnover of Coopernic, it "only" owned an equal share $(20 \%)$ of the group. New members must buy in by acquiring shares.

Management. Buying groups are run on a day-to-day basis by a dedicated staff and are controlled by a Board of Directors that is made up of high-rank representatives from the members (often the chief executive officer or vice president of purchasing). In some groups, all members are represented, whereas in others these positions are elected. The board decides on the broad strategy for the years ahead and also deals with membership.

Compensation. Buying groups are nonprofit organizations that are funded by membership subscriptions. The cost of running the group operation is shared by all members and, likewise, any operating surpluses are returned to the members. Subscription payments may vary across the members. For example, in AMS Sourcing, half of group income is levied equally, but the remainder is made up of subscription units that are levied according to member size.

\section{Buying Groups Versus Other Interorganizational Collaboration Forms in Marketing}

The bulk of marketing's interorganizational literature focuses on collaborative arrangements among vertically related firms. Buying groups are horizontal alliances (i.e., alliances between firms operating at the same stage of the value chain). In the marketing literature, two of the most popular types of horizontal alliances are marketing and research-and-development $(\mathrm{R} \& \mathrm{D})$ alliances. In marketing alliances, firms combine their marketing efforts and thus integrate their brand names to a certain extent (Bucklin and Sengupta 1993). In R\&D alliances, the key lies in the transfer of technological knowledge between firms (Rindfleisch and Moorman 2001). Although related to buying groups, the different objectives of marketing and $R \& D$ alliances result in different types of member contributions, interactions, and tensions, and these alliances may therefore affect

${ }^{2}$ Because we focus on grocery retailing, retailers in our sample can only belong to one grocery group concurrently. firm performance in different ways (Das, Sen, and Sengupta 1998). In Table 1, we compare the three types of horizontal alliances. ${ }^{3}$

\section{Conceptual Framework}

A retailer gains from a buying group membership when it can capture the benefits from the accumulated purchasing power of the different retailers in the group. However, unlike retailer power generated by (single) firm size, buying group power originates from the "virtual consolidation" of the demand of individual retail firms, each with a different set of resources and interests. The group diversity, or specific mix of retailers in a group, may therefore affect the extent to which each member is able to benefit from the buying group's scale.

To capture this diversity, we follow Gomes-Casseres (1994) and Lazzarini (2007) and distinguish group characteristics from member characteristics. Group characteristics are general attributes of a buying group that differ across groups but not across retailers within groups. Member characteristics are attributes of an individual group member relative to other members. Whereas group characteristics affect each retailer in the buying group equally, member characteristics determine the benefits that accrue disproportionally to one retailer versus another within the same group. We consider the variety among the group members in terms of their size (size heterogeneity) and market operations (market scope) as group characteristics and include the relative size of a retailer within the group and its market overlap relative to its group fellows as member characteristics. ${ }^{4}$ Figure 1 graphically depicts our conceptual framework. Before we turn to our hypotheses on the moderating effects of the group and member characteristics, we first discuss the baseline effect of buying group scale on retailer performance.

\section{The Effect of Buying Group Scale on Retailer Performance}

We define buying group scale as the aggregate sales volume brought by the buying group members. Buying group scale

${ }^{3}$ For a comparison of horizontal with vertical alliances, see Rindfleisch (2000). Buying groups also differ from alliance networks or portfolios, which are collections of firms that are connected through multiple alliances (Cui and O'Connor 2012). In contrast, a buying group is a single (multilateral) alliance involving multiple members.

${ }^{4}$ Although the group and member characteristics in our framework are defined along the same dimensions (size and market operations), they are clearly distinct. For example, despite the wide market scope of the IRTS group in 2006, which covered stores in 26 countries worldwide, there was relatively little market overlap between its two members, with one focusing on the European markets while the other had expanded much farther afield. In contrast, in the buying group Opera, which also is characterized by a wide geographic-market scope, there is high geographic overlap between the two members. The NAF group, in contrast, has a narrow scope and, on average, retailers in the group have little overlap with their fellow members (though the extent of overlap varies across retailers). 
TABLE 1

Buying Groups Versus Other Horizontal Alliances

\begin{tabular}{|c|c|c|c|}
\hline & Buying Groups & Marketing Alliances & R\&D Alliances \\
\hline Primary focus & $\begin{array}{l}\text { Operational: increase productivity } \\
\text { through the provision of scale } \\
\text { economies }\end{array}$ & $\begin{array}{l}\text { Strategic: stimulate demand } \\
\text { (e.g. , share brand names, } \\
\text { advertising, promotions, or } \\
\text { distribution channels) }\end{array}$ & $\begin{array}{l}\text { Strategic: innovate (e.g., develop } \\
\text { new products or technologies) }\end{array}$ \\
\hline $\begin{array}{l}\text { Number of } \\
\text { members }\end{array}$ & $\begin{array}{l}\text { Usually multilateral, although } \\
\text { some consist of only two members }\end{array}$ & $\begin{array}{l}\text { Usually dyadic, although some } \\
\text { consist of more than two members }\end{array}$ & Dyadic or multilateral \\
\hline $\begin{array}{l}\text { Life span and } \\
\text { membership } \\
\text { dynamics }\end{array}$ & $\begin{array}{l}\text { Life span is open-ended. } \\
\text { Membership is in a continuous } \\
\text { state of flux. }\end{array}$ & $\begin{array}{l}\text { Life span is fixed. Membership is } \\
\text { stable. }\end{array}$ & $\begin{array}{l}\text { Life span is fixed. Membership is } \\
\text { stable. }\end{array}$ \\
\hline $\begin{array}{l}\text { Type of member } \\
\text { contributions }\end{array}$ & $\begin{array}{l}\text { Members contribute similar } \\
\text { resources, namely, scale and } \\
\text { price information. }\end{array}$ & $\begin{array}{l}\text { Members typically contribute } \\
\text { dissimilar resources (e.g., brand } \\
\text { image, access to distribution } \\
\text { channels). }\end{array}$ & $\begin{array}{l}\text { Members typically contribute dis- } \\
\text { similar resources (e.g., technology } \\
\text { domains, laboratories, equipment). }\end{array}$ \\
\hline $\begin{array}{l}\text { Sharing and } \\
\text { safeguarding of } \\
\text { knowledge }\end{array}$ & $\begin{array}{l}\text { Price information is shared with } \\
\text { the "third-party" buying group. } \\
\text { Opportunistic learning is deterred } \\
\text { by not sharing price information } \\
\text { among the members of the group. }\end{array}$ & $\begin{array}{l}\text { Marketing knowledge is shared } \\
\text { among the alliance members. } \\
\text { Vulnerability to opportunistic } \\
\text { learning is more pronounced than } \\
\text { in buying groups. }\end{array}$ & $\begin{array}{l}\text { Technological knowledge is shared } \\
\text { and generated among the alliance } \\
\text { members. This may result in firms } \\
\text { trying to get ahead of their } \\
\text { partners in a "race to learn." Thus, } \\
\text { vulnerability to opportunistic } \\
\text { learning is more pronounced than } \\
\text { in marketing alliances. }\end{array}$ \\
\hline $\begin{array}{l}\text { Primary source } \\
\text { of coordination } \\
\text { difficulties }\end{array}$ & $\begin{array}{l}\text { Diverging member interests cause } \\
\text { conflict. }\end{array}$ & $\begin{array}{l}\text { Conflicts occur over the distribution } \\
\text { of earnings; proportionate } \\
\text { allocation of value created tends } \\
\text { to be difficult because partners } \\
\text { contribute dissimilar and often } \\
\text { intangible resources. }\end{array}$ & $\begin{array}{l}\text { Conflicts ensue over the distribution } \\
\text { of earnings; proportionate } \\
\text { allocation of value created tends to } \\
\text { be difficult because partners } \\
\text { contribute dissimilar and often } \\
\text { intangible resources. }\end{array}$ \\
\hline $\begin{array}{l}\text { Tie strength } \\
\text { between } \\
\text { members }\end{array}$ & $\begin{array}{l}\text { Weak-close to the market } \\
\text { anchor of the vertical integration } \\
\text { continuum }\end{array}$ & $\begin{array}{l}\text { Moderate-between market } \\
\text { (arm's-length transactions) and } \\
\text { hierarchy (internalization) }\end{array}$ & $\begin{array}{l}\text { Moderate-between market } \\
\text { (arm's-length transactions) and } \\
\text { hierarchy (internalization) }\end{array}$ \\
\hline $\begin{array}{l}\text { Exemplary } \\
\text { marketing } \\
\text { studies }\end{array}$ & - & $\begin{array}{l}\text {-Bucklin and Sengupta (1993) } \\
\text {-Luo, Rindfleisch, and Tse (2007) } \\
\text {-Swaminathan and Moorman } \\
\text { (2009) } \\
\text { •Xiong and Bharadwaj (2011) }\end{array}$ & $\begin{array}{l}\text { - Luo, Rindfleisch, and Tse (2007) } \\
\text { - Rindfleisch and Moorman (2001) } \\
\text { - Sivadas and Dwyer (2000) } \\
\text {-Xiong and Bharadwaj (2011) }\end{array}$ \\
\hline
\end{tabular}

positively affects retailer performance for two reasons. First, by using their clout and intensifying competition among their suppliers (Li 2012), larger buying groups can keep suppliers "on their toes" and extract better buy-in prices. Lower buy-in prices may result in higher margins (a supply-side advantage) but also enable retailers to (selectively) reduce retail prices, which in turn may increase retailer sales (a demand-side advantage) (Dobson 2002). In addition to negotiating better prices, buying groups may provide access to own-brand ranges, regional products, and bespoke products that cannot be produced cost effectively on a smaller scale, which may further increase the sales of their members (IGD 2012).

Second, the ability of a buying group to increase retailer performance also depends on the ability of the group to deliver benefits to suppliers. Dealing with larger buying groups assures suppliers of a minimum quantity of purchases that individual buyers cannot guarantee (Majumdar et al. 2007), thus allowing for an efficient scale for production and opportunities for further investments or innovation. For example, AMS Sourcing's managing director, Bert
Swartsenburg, has indicated in an interview that "for a supplier, you can reach economies of scale, you can expand your volumes, and you don't pay any fee to take part in our project" (ESM 2012, p. 61). In summary, dealing with larger buying groups potentially offers volume advantages to suppliers, which in turn may help larger groups in negotiating with suppliers. Thus,

$\mathrm{H}_{1}$ : Buying group scale increases retail members' performance.

\section{The Moderating Role of Group Characteristics}

Size heterogeneity. Size heterogeneity captures the diversity among the buying group members in terms of their size (Yin, Wu, and Tsai 2012). Size symmetry discourages the development and expression of conflict because the firms have equivalent stakes in the buying group (cf. Kumar, Scheer, and Steenkamp 1995). Firms of more similar size have been shown to empathize more with each other's situation and have a deeper appreciation of each other's strengths, vulnerabilities, and needs ( $\mathrm{Li}$ and Greenwood 2004). In contrast, firms of different sizes are less 
FIGURE 1

Conceptual Framework

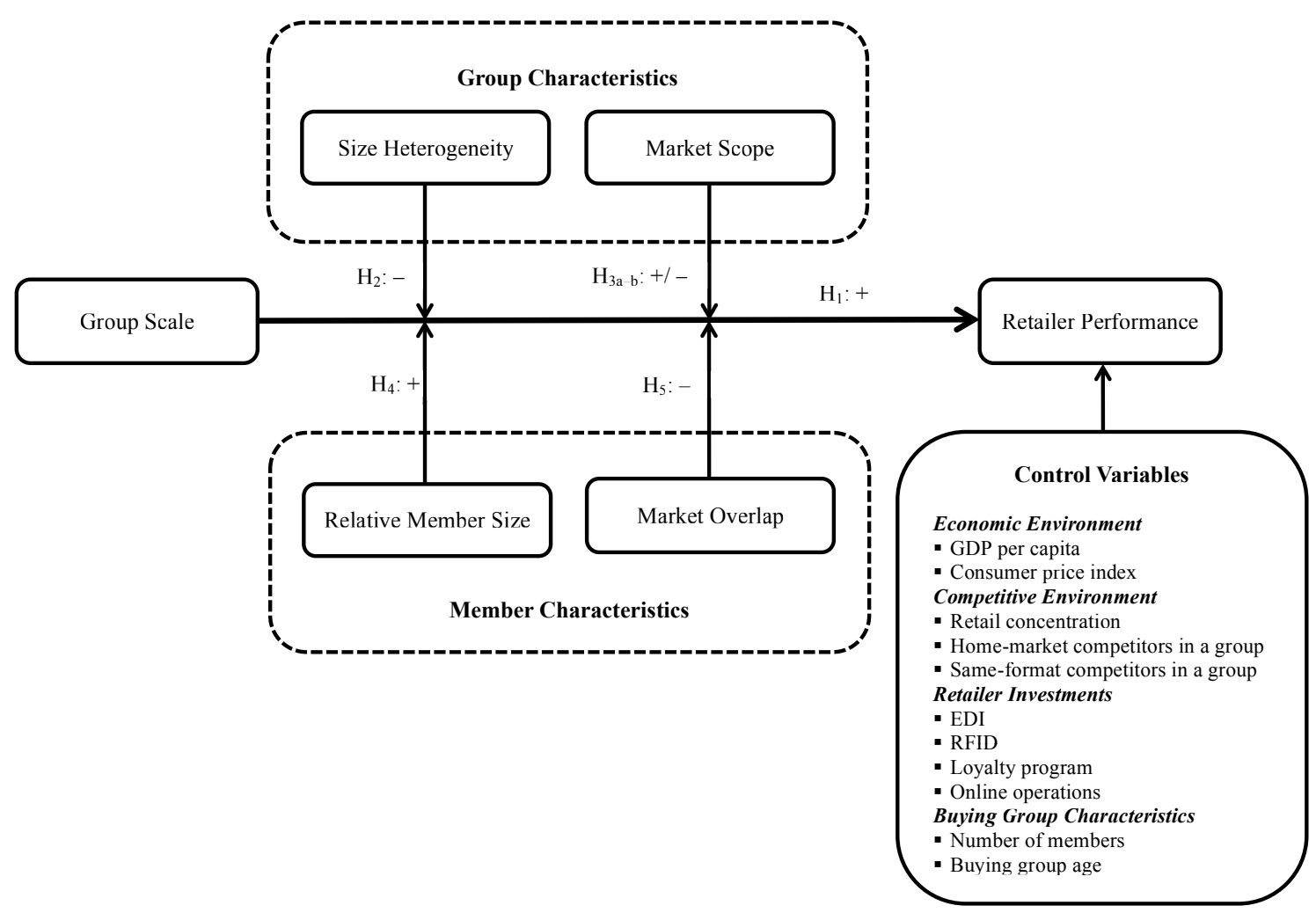

likely to fully understand each other's position. They are less likely to be trusting, are more motivated to engage in conflict, and have fewer reasons to restrain themselves (Kumar, Scheer, and Steenkamp 1995). As a result, firms of different sizes may have more difficulty finding common ground (Rowley et al. 2005), for example, in determining which range of goods to buy through the buying group or which suppliers to negotiate with.

In addition, suppliers may be more skeptical about dealing with buying groups that are characterized by higher size heterogeneity. They may question the advantage of collaborating with smaller retailers that are "riding on the coattails" of the larger retailers in the group. Large brand owners, potentially the most valuable partners for buying groups, may be particularly guarded in dealing with asymmetric groups (MinnesotaLife 2009), which may reduce the positive effect of buying group scale on retailer performance. Rewe, for example, was by far the largest member of Coopernic, and for suppliers that already dealt with Rewe, Coopernic's ability to deliver additional distribution was reduced. Thus,

$\mathrm{H}_{2}$ : The larger the size heterogeneity within the buying group, the smaller the effect of buying group scale on retail members' performance.

Market scope. Market scope reflects the buying group's diversity of markets served and refers to both geographic and product markets (Jayachandran, Gimeno, and Varadarajan 1999). Prior research has shown repeatedly that a broad market scope provides information benefits (Gulati 1999). In our buying group setting, sharing price information enables the buying group to compare buy-in prices across the markets where the members operate. When confronted with any price differentials, the group can press suppliers for standardized (i.e., lower) terms (Majumdar et al. 2007). A broader market scope may also be beneficial to suppliers by providing access to international markets, 5 an advantage the group may use in turn to demand further concessions. However, a broader market scope also has downsides. Buying groups with a broader market scope may be less efficient in aggregating their purchases given that members are more likely to have different priorities depending on the preferences of their clientele and their location (Inderst and Mazzarotto 2009). As a result, it may be more difficult to agree on the range of products to be sourced through the group. Indeed, "reconciling the different interests of members ... is a challenge requiring no small amount of diplomatic skill" (IGD 2006, p. 13), especially because local adaptation is a key concern to retailers in creating a competitive advantage. This is, for example, explicitly reflected in the mission statement of Alidis, a buying group operating in 12 European countries: "Our aim is to increase

5This is an advantage that buying groups themselves are particularly keen to promote. For example, IRTS "advertised" on its website that one of its main functions was "to act as a facilitator for smaller and medium sized supplier companies that wish to access international markets" (IGD 2006, p. 96). 
the common product ranges of all ... members, without this leading to the loss of local adaptation" (Constan Dacosta, Alidis President, May 2009, italics added). Because it is unclear a priori whether the downsides outweigh the information benefits of a broader market scope, we offer alternative hypotheses:

\footnotetext{
$\mathrm{H}_{3 \mathrm{a}}$ : The broader the market scope of the buying group, the larger the effect of buying group scale on retail members' performance.

$\mathrm{H}_{3 \mathrm{~b}}$ : The broader the market scope of the buying group, the smaller the effect of buying group scale on retail members' performance.
}

\section{The Moderating Role of Member Characteristics}

The extent to which a retailer benefits from participation in a buying group depends not only on the composition of the group but also on the position of the retailer within the group. The relative size of the retailer within the buying group and its market overlap with the group may explain why some retailers benefit more than others from a buying group's scale.

Relative member size. Member size refers to a retailer's size relative to its peers within the buying group. At first glance, one might argue that relatively smaller group members should be able to benefit more from buying group scale than relatively larger members because the smaller members may gain disproportionately from the added purchasing power from the larger members. The opposite, however, is likely to be true. Because a relatively larger retailer contributes disproportionately to the total scale of the buying group, it is able to threaten with departure from the group unless it also obtains disproportionate membership benefits (Lazzarini 2007). The threat of exit is credible in that a larger member's exit would have a crippling effect on those (smaller members) that remain by undermining existing agreements with suppliers and reducing the group's ability to extract future concessions from suppliers. Accordingly, larger members have more leverage and are therefore better able to steer group activities toward their own goals (cf. Cui and O'Connor 2012), for example, by sourcing goods from their preferred local source even when that is not the cheapest option. In summary, we expect the following:

$\mathrm{H}_{4}$ : The larger the relative size of a retail member within a buying group, the larger the effect of buying group scale on that retail member's performance.

Market overlap. Market overlap is the similarity between the markets served by a retailer and the other members of the buying group to which it belongs. Market overlap may range from having no markets in common with the rest of the group to having completely overlapping markets. Firms that operate in more similar market domains engage in more direct competition (Oxley and Sampson 2004). A high degree of competition between a retailer and its group peers may stand in the way of effectively deploying the group to gain a stronger competitive position. Collaborating with firms that operate in the same market domain undermines the rarity of the resources a firm gleans from buying group participation (e.g., more favorable con- tracts with suppliers, access to unique products). Thus, the more a retailer's market domain overlaps with that of its peers, the less it will benefit from the group, because advantages obtained from group participation are also available to direct competitors. For example, geographic overlap with members of established groups has been cited as a key motivation for the founding members of Coopernic to form a new group rather than allying with one of the established groups. Thus,
$\mathrm{H}_{5}$ : The larger the market overlap between a retail member and the buying group, the smaller the effect of buying group scale on that retail member's performance.

\section{Data}

\section{Study Overview}

We conducted two studies to test our hypotheses. Study 1 serves as a baseline investigation of whether buying group membership increases retailer performance on average. Study 2 provides a test of our conceptual framework. It enables us to assess whether the relative performance differences among retailers that are in a buying group can be explained by the composition of the group and the retailer's position within the group. We first describe the data and the performance measures used in Studies 1 and 2 and then discuss both studies in more detail.

\section{Data}

We used historical analysis (Golder and Tellis 1993) and traced the buying group membership over 15 years (between 1997 and 2011) of all European grocery retailers that were ranked as a European top 100 player (on the basis of retail banner sales) at one point in time during our 15year observation window. This approach implies that for all retailers, 15 years of information is taken into account, even if a retailer was too small to appear in the top 100 at the start of our observation period. Likewise, we include information on retailers that were no longer active by the end of the observation window. In total, we gathered information on 138 retailers, resulting in a Study 1 data set of 1,692 retailer-year observations.

Of these 138 retailers, 63 were members of a buying group at one time during our window of observation, resulting in a Study 2 data set of 727 retailer-year observations and covering 24 buying groups. We obtained the group membership information from Planet Retail. We validated this information by conducting an extensive online search of trade publications, annual reports, and press releases. Of the 24 buying groups we traced, 9 were dissolved before the end of the observation window. In most cases, the decision to dissolve the groups was a consensual decision as members felt that their interests had diverged too much. Some groups fell apart after a central member left the group to join a different group (e.g., Eurolec) or because of merger and acquisition moves of one of their members (e.g., Opera). 
Key performance measure: retailer productivity. Because buying group benefits may arise on both the supply ("input") and demand ("output") sides, we use a performance metric that reflects both dimensions: retailer productivity. This metric can be captured by estimating technical efficiencies through the stochastic frontier method (e.g., Gauri 2013; Gauri, Pauler, and Trivedi 2009). In the stochastic frontier approach, a transformation function for the conversion of inputs into output is specified in which the error term is split into a random component $\mathrm{v}_{\mathrm{t}, \mathrm{r}}$ and a timevarying, nonnegative inefficiency component $\mathrm{u}_{\mathrm{t}, \mathrm{r}}$. While the purely random shocks are absorbed by the random component, $\mathrm{u}_{\mathrm{t}, \mathrm{r}}$ captures the inefficiency of converting inputs into output. We use a Cobb-Douglas function to link retail inputs to output and a half-normal distribution for the inefficiency components (Dutta, Narasimhan, and Rajiv 1999). The stochastic frontier is estimated over the data pooled over all 138 retailers and all years. The efficiency or productivity score for each retailer, in each year, is then

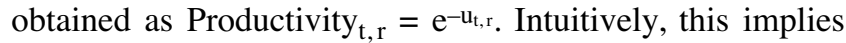
that, for given retailer inputs, each retailer is compared with a "best-practice" standard, which is estimated from the data.

In line with previous retail productivity studies (see, e.g., Gauri 2013; Gauri, Pauler, and Trivedi 2009), we use sales revenue (Sales) as the output metric. We include four types of controllable inputs that are available from Planet Retail for all retailers in our data set: (1) store selling area, (2) store formats operated, (3) nongrocery retail activities, and (4) international operations. First, store selling area (Area) is a good measure of the capital used in a retail operation (Gauri 2013). Store energy costs and other major capital inputs, such as refrigeration equipment and lighting, shelving and display cases, and front-end checkout equipment, are highly correlated with store selling area. Second, providing different levels of distribution service and price points entails different costs for grocery retailers (Gauri 2013). Store formats are traditionally classified according to four broad dimensions: breadth and depth of product assortment, price, accessibility of location, and convenience (for a more complete discussion, see Betancourt and Gautschi 1988). We include the share of big box operations, price fighter operations, neighborhood operations, and online operations in the retailer's portfolio to capture formats that excel at, respectively, assortment, price focus, physical accessibility, and convenience. We further capture the retailer's investments into nongrocery services, such as banking services and travel, its share of wholesaling operations, and the number of countries in which it operates, as proxies for operational expenses. All input variables are lagged. Web Appendix W1 offers more details.

Alternative performance measures: Cost of goods sold and sales. We test our theoretical model using two alternative dependent variables, cost of goods sold (COGS) and sales. Cost of goods sold and sales occupy a place in our theorizing as two pathways through which buying groups may increase retailer productivity. Our theorizing posits that buying groups may have a negative impact on COGS through their effect on buy-in prices. We have also argued that buying groups may have a positive impact on retailer sales when retailers pass on (part of) the reduced buy-in prices to the consumer in the form of reduced retail prices and/or when retailers gain access to product ranges otherwise unavailable to them (e.g., own-brand ranges, regional products).

We assembled data on COGS from Bureau van Dijk's Orbis database and the retailers' financial reports. Because not all private companies share financial information, COGS data are available for only a subset $(\mathrm{N}=60)$ of the retailers in our sample. In addition, COGS data were often available for a shorter time window, which further reduced the number of observations. In total, 594 (424) retailer-year observations were available for estimation in Study 1 (Study 2). As such, the results for the COGS model should be regarded as indicative rather than definitive. Sales data are available for all retailers and all time periods and are taken from Planet Retail.

Covariates. Table 2 provides a detailed overview of the measures for the covariates used in Studies 1 and 2. The continuous variables are log-transformed to reduce skewness.

\section{Descriptive Information}

The 138 retailers in our Study 1 sample vary substantially. Retailers originate from 26 different home markets, covering both mature (e.g., Germany, Spain) and developing retail markets (e.g., Russia, Serbia). Whereas some retailers in the sample are true multinational companies operating in more than 30 countries (e.g., Carrefour), others operate exclusively in their country of origin (e.g., Spain's Unide). Our sample covers both small and large retailers, with retailer banner sales ranging from approximately $€ 14$ million (Ukraine's Fozzy) to more than $€ 100,000$ million (e.g., Carrefour). Some players are market leaders in their home market (e.g., Lithuania's Maxima), whereas others only hold a small fraction of their domestic market (e.g., the United Kingdom's Wilkinson's). Their productivity in the last year of our observation window ranges from $60 \%$ to $85 \%$, with players such as Schlecker and Tengelmann occupying the lower side of the range and Intermarché and Edeka on the higher side. ${ }^{6}$ In addition, the retailers that are buying group members (our Study 2 sample) vary significantly. They originate from 17 home markets and include domestic (e.g., Finland's Wihuri) and international (e.g., Casino) players as well as small (e.g., Ahorramas; €334 million banner sales) and large (e.g., Carrefour) retailers.

\footnotetext{
${ }^{6}$ We also observe significant variation over time. Some retailers, such as Delta $\mathrm{M}$ and Agrokor, score consistently below average (productivity scores between $62 \%$ and $66 \%$ ), whereas others, such as Lekkerland and Safeway (UK), always perform above the $80 \%$ mark. Yet another set of retailers has productivity scores that vary above and below average over time, such as Fozzy, whose productivity scores range from $47 \%$ to $75 \%$ over our window of observation.
} 
TABLE 2

Measurement of Independent Variables

\section{Variablea \\ Group Characteristics}

Group scale

Size heterogeneity

Geographic-market scope

Product-market scope

Number of members

Buying group age

\section{Retailer Characteristics}

Relative member size

Geographic-market overlap

Product-market overlap

EDI

RFID

Loyalty program

Online operations

Retailer size

Market position in home market Importance of home market
Operationalizationb

The sum of the total banner sales of all buying group members:

$\sum_{r=1}^{R_{g}}$ Sales $_{r, g}$, where Sales ${ }_{r, g}$ represents the sales of retailer $r$ in buying group $g$, and $R_{g}$ is

A Herfindahl-like index,

$\sum_{\mathrm{r}=1}^{\mathrm{R}}\left(\frac{\text { Sales }_{\mathrm{r}}}{\text { Sales }_{\mathrm{g}}}\right)^{2}$

based on the proportion of each retailer r's $\left(r=1, \ldots, R_{g}\right)$ sales within the buying group's sales:

Sales $_{\mathrm{g}}=\sum_{\mathrm{r}=1}^{\mathrm{R}_{\mathrm{g}}}$ Sales $_{\mathrm{r}, \mathrm{g}}$.

The closer the index approaches one, the more heterogeneous the buying group is in terms of the size of its members.

The total number of countries in which the buying group members operate

The total number of store formats (including the typical formats such as supermarkets, discount stores, and hypermarkets as well as more specialized formats such as forecourt stores, drugstores, pet shops, organic food stores, etc.) operated by the buying group members The number of retailers affiliated with the buying group

The difference between the year of operation and the year in which the buying group was founded

$$
\frac{\sum_{r=1}^{R_{g}-1} \frac{\text { Sales }_{r, g}}{\operatorname{Sales}_{r^{\prime}, g}}}{R_{g}-1}, \begin{aligned}
& \text { where Sales } r_{r^{\prime}, g} \text { are the sales of fellow group member } r^{\prime}\left(r^{\prime} \neq r, r^{\prime}=1, \ldots, R_{g}-\right. \\
& \text { in buying group } g
\end{aligned}
$$$$
1-\frac{\sum_{\mathrm{c}=1}^{\mathrm{C}}\left|\frac{\text { Sales }_{\mathrm{r}, \mathrm{c}}}{\text { Sales }_{\mathrm{r}}}-\frac{\text { Sales }_{\mathrm{g}^{\prime}, \mathrm{c}}}{\text { Sales }_{\mathrm{g}^{\prime}}}\right|}{\mathrm{C}}
$$

where Sales ${ }_{r, c}$,represents the sales of retailer $r$ in country $c$ and Sales $_{\mathrm{g}^{\prime}, \mathrm{c}}$ represent the sales of the buying group exclusive of focal retailer $r$ (denoted by $g^{\prime}$ ) in country $c$, respectively. $C$ equals the total number of countries in which the buying group members are active. A value of 0 indicates no overlap in retailers' operations, while a value of 1 indicates complete overlap.

$$
1-\frac{\sum_{\mathrm{f}=1}^{\mathrm{F}}\left|\frac{\text { Sales }_{\mathrm{r}, \mathrm{f}}}{\text { Sales }_{\mathrm{r}}}-\frac{\text { Sales }_{\mathrm{g}^{\prime}, \mathrm{f}}}{\text { Sales }_{\mathrm{g}^{\prime}}}\right|}{\mathrm{F}},
$$

where Sales $s_{r, f}$ represents the sales of retailer $r$ through format $f$ and Sales $_{g^{\prime}, f}$ represents the sales of the buying group exclusive of focal retailer $r$ (denoted by $g^{\prime}$ ) through format $f$, respectively. $F$ equals the total number of formats the buying group members operate. A value of 0 indicates no overlap in retailers' operations, and a value of 1 indicates complete overlap.

Dummy variable that equals 1 if the retailer invests in EDI; 0 otherwise

Dummy variable that equals 1 if the retailer invests in RFID; 0 otherwise

Dummy variable that equals 1 if the retailer runs a loyalty program; 0 otherwise

Dummy variable that equals 1 if the retailer runs a web store; 0 otherwise

The retailer's total number of stores

The retailer's market share in its home market

The share of home market sales in total retailer sales 


\begin{tabular}{|c|c|}
\hline Variablea & Operationalization ${ }^{b}$ \\
\hline \multicolumn{2}{|l|}{ Economic Environment } \\
\hline GDP per capita & GDP per capita in the retailer's home market \\
\hline Consumer price index & Consumer price index in the retailer's home market \\
\hline \multicolumn{2}{|l|}{ Competitive Environment } \\
\hline Retail concentration & Cumulative market share of the five largest grocery retailers in the retailer's home market \\
\hline $\begin{array}{l}\text { Home-market competitors in a } \\
\text { group }\end{array}$ & The fraction of home-market competitors already active in a buying group \\
\hline $\begin{array}{l}\text { Same-format competitors in a } \\
\text { group }\end{array}$ & The fraction of same-format competitors already active in a buying group \\
\hline \multicolumn{2}{|c|}{$\begin{array}{l}\text { aAll of the buying group variables and the three focal retailer variables (relative member size, geographic-market overlap, and product-market } \\
\text { overlap) are defined using data on all buying group members, including retailers that never reached a top } 100 \text { position in the } 15 \text { years that } \\
\text { span our observation window and that are therefore not represented in our sample. Except for GDP per capita and the consumer price index, } \\
\text { which are taken from the World Bank Indicators, all variables are derived from Planet Retail. } \\
\text { bFor reasons of simplicity, we do not portray the year subscript t. All retailer performance information is related to group and member charac- } \\
\text { teristics from the moment the retailer becomes active in a buying group until (1) the moment the retailer leaves the buying group, ( } 2 \text { ) the buy- } \\
\text { ing group is dissolved, or (3) the end of the observation window is reached (when the retailer is still an active buying group member). Retailers } \\
\text { may enter a new group after leaving a previous one. These shifts are tracked by the evolution in the independent variables in our framework. }\end{array}$} \\
\hline
\end{tabular}

On average, a buying group consists of 6 members, but it can have as few as 2 (e.g., Opera) or as many as 15 (e.g., Superunie in 2007). In some instances, the number of members in the group remained stable over time, as was the case for Coopernic, whose 5 founding members remained the only members during the entire window of observation. Other groups began with a smaller number of members and gradually added members over the years. For example, AMS Sourcing started in 1989 with 3 members but, in later years, comprised more than 10 members. Retail members also left groups over time. For example, from 1992 onward, 8 retailers left AMS Sourcing while others joined the group to replace the departing members, keeping the balance fairly stable from 1992 onward. Some of these exits followed after members were acquired by nonmember retailers, as in the case of Safeway (UK) leaving AMS Sourcing. In other instances, the exit followed the member's desire to join a rival buying group, as was the case with Delhaize, which left EMD to join AMS Sourcing in 2009.

The aggregate sales brought by the group members range from $€ 5$ billion to $€ 198$ billion. This aggregate scale is sometimes achieved by pooling the sales of similarly sized businesses, as is the case for Markant, for example. In other instances, buying group scale is attained by pooling the sales of one or more large dominant members with the sales of several smaller retailers. For example, although buying group Coopernic had five members, $40 \%$ of its aggregate turnover was attributable to just one retailer (Rewe). In a similar vein, Ahold has been cited as the (too) dominant partner in the AMS Sourcing group. On average, the retailers in a buying group collectively serve 19 geographic markets and operate 12 store formats. Whereas some groups are characterized by a large overlap in the operations of their members (e.g., Ifa Espanol and Superunie are strictly national in scope), others have members that mainly operate in different countries (e.g., AMS Sourcing). Web Appendix W2 provides an overview of the buy- ing groups in our study, and Web Appendix W3 contains descriptive statistics and correlations.

\section{Study 1}

\section{Overview}

The objective of Study 1 is to explore whether buying group membership alters retailers' performance. We exploit the quasinatural experiment setting of our data in which we observe retailers that entered a buying group (the treatment group) and retailers that did not enter a buying group (the control group) before and after entry. We relate group membership as a structural break variable to retailers' (1) productivity, (2) COGS, and (3) sales, thereby allowing for a structural change in the level of the performance metrics. To control for the nonrandom assignment of retailers to buying groups, we use a Heckman control function approach.

\section{Model}

The multilevel model to quantify whether buying group membership increases retailer performance is as follows:

(1) Performance $\mathrm{t}_{\mathrm{t}, \mathrm{r}}=\pi_{0}+\pi_{1}$ GroupMember $_{\mathrm{t}, \mathrm{r}}$

$$
\begin{aligned}
& +\sum_{\mathrm{k}=1}^{2} \pi_{\mathrm{k}+1} \text { EconomicEnvironment }_{\mathrm{t}, \mathrm{r}} \\
& +\sum_{\ell=1}^{3} \pi_{3+\ell} \text { CompetitiveEnvironment }_{\mathrm{t}-1, \mathrm{r}} \\
& +\sum_{\mathrm{m}=1}^{4} \pi_{6+\mathrm{m}} \text { Investments }_{\mathrm{r}}+\pi_{11} \rho_{\mathrm{t}, \mathrm{r}}+\mathrm{e}_{\mathrm{r}}+\varepsilon_{\mathrm{t}, \mathrm{r}},
\end{aligned}
$$

where Performance is the dependent variable of interest and can refer to retailer productivity, COGS, or sales. Although we use one equation to represent all three performance met- 
rics for convenience, we estimate the parameters individually. The discrete independent variable GroupMember equals 1 if retailer $r$ is a buying group member at time $t$ and 0 otherwise.

In addition to the focal independent variable GroupMember, we include nine control variables in the model. The first set of control variables pertains to the retailer's economic environment, where we include gross domestic product (GDP) per capita and the consumer price index. We also control for the retailer's competitive environment by including market concentration, the fraction of home-market competitors, and the fraction of same-format competitors already active in a group. ${ }^{7}$ Finally, we control for various retailer investments that may affect retailer performance. We distinguish between the retailer's supplier-centered investments (namely, retailer investments in electronic data interchange [EDI] and radio frequency identification [RFID]), which may increase its operational efficiency, and the retailer's customer-centered investments (namely, retailer investments in loyalty programs and online operations), which may create customer value and thereby increase sales.

The random effect $e_{r}$ corrects for the grouping of the data within retailers and is normally distributed over retailers. The error term $\varepsilon_{\mathrm{t}, \mathrm{r}}$ is normally distributed with zero mean and variance-covariance matrix $\sigma^{2}$. The term $\rho_{\mathrm{t}, \mathrm{r}}$ accounts for the fact that retailers do not join buying groups randomly and is obtained by estimating a probit model, as we explain next.

\section{Controlling for Endogeneity}

Retailers do not randomly decide to join a buying group but, rather, do so hoping to improve performance. To account for this, we estimate a probit model for the "treatment" or buying group decision. We relate this decision to a set of environmental (economic and competitive) factors that capture the retailer's motivation to join a buying group on the one hand and the retailer's attractiveness to a group on the other hand.

As to the economic environment, we include GDP and the consumer price index. Retailers may be more motivated to join a buying group when the economic climate is bleak (as reflected in a low GDP per capita) and when price competition is fierce (as reflected in a low consumer price index). As to the competitive environment in which the retailer operates, we include market concentration. Retailers may be more motivated to join a buying group when rivalry is intense, as reflected in a high market concentration. We also include the fraction of home-market competitors and same-format competitors engaging in buying group activities to account for imitation and learning effects on the one hand and potential preemption threats on the other. Finally, we include a set of retailer factors that capture the retailer's

${ }^{7} \mathrm{As}$ is postulated in competitive cognition theory, companies do not view their competitive landscape as homogeneous and attach more weight to prior decisions by retailers with which they share key attributes. We consider two such attributes: the retailers' home market (or country of origin) and the retailers' store format. appeal for buying groups and, thus, the likelihood of acceptance into a group, should it apply to join one. We include retailer size, the market position of the retailer in its home market, and the importance (or share) of the retailer's home market in its overall operations (because home markets are still very important in grocery retailing; Corstjens and Lal 2012). Formally, we estimate the following equation:

$$
\text { (2) } \begin{aligned}
\text { GroupMember }_{\mathrm{t}, \mathrm{r}} & =\delta_{0}+\sum_{\mathrm{k}=1}^{2} \delta_{\mathrm{k}} \text { EconomicEnvironment }_{\mathrm{t}, \mathrm{r}} \\
& +\sum_{\ell=1}^{3} \delta_{2+\ell} \text { CompetitiveEnvironment }_{\mathrm{t}-1, \mathrm{r}} \\
& +\sum_{\mathrm{m}=1}^{3} \delta_{5+\mathrm{m}} \text { RetailerAppeal }_{\mathrm{t}-1, \mathrm{r}}+\varepsilon_{\mathrm{t}, \mathrm{r}} .
\end{aligned}
$$

The error term $\varepsilon_{\mathrm{t}, \mathrm{r}}$ is normally distributed with zero mean and variance-covariance matrix $\sigma^{2}$. This probit model allows us to capture the generalized residual $\rho$ as $\{$ GroupMember $\times[\phi(\mathrm{Z} \delta) / \Phi(\mathrm{Z} \delta)]\}-\{(1-$ GroupMember $) \times[\phi(\mathrm{Z} \delta) /$ $\Phi(Z \delta)]\}$, where $\phi(\cdot)$ and $\Phi(\cdot)$ represent the probability density and cumulative density functions of the standard normal distribution and the ratio of both represents the inverse Mills ratio (Gourieroux et al. 1987). The vectors $Z$ and $\delta$ represent all independent variables and estimates as used and obtained in Equation 2. The generalized residual $\rho$ is added to Equation 1 to account for the fact that retailers do not join buying groups randomly.

\section{Estimation Results}

Before turning to the performance results (Equation 1)our main interest in this study - we briefly discuss the findings for Equation 2, which appear in Table 3. Retailers are less likely to be part of a buying group when the consumer price index is high $(\delta=-.013, p<.01)$ and when their home markets are highly concentrated $(\delta=-.010, p<.05)$. In contrast, they are more likely to participate in a buying group when GDP per capita is higher $(\delta=.014, p<.10)$, when more home-market competitors $(\delta=4.041, p<.01)$ and same-format competitors $(\delta=3.309, p<.01)$ do so as well, when they are larger in size $(\delta=.025, p<.01)$, when they occupy a higher market share in their home market $(\delta=$ $.045, p<.01)$, and when their home market represents a more substantial share of their revenues $(\delta=.009, p<.01)$.

Turning to the performance results, which appear in Table 4, we find that buying group membership positively affects retailer productivity $\left(\pi_{1}=.006, p<.01\right)$ and sales $\left(\pi_{1}=1.615, p<.10\right)$ and negatively affects COGS $\left(\pi_{1}=\right.$ $-3.425, p<.01) .{ }^{8}$ Collectively, these results support the

${ }^{8}$ For the productivity model, the multilevel model captures $47 \%$ of the level-one variation (i.e., the across-time within-retailer variation) and $12 \%$ of the level-two variation (i.e., the betweenretailer variation). For the sales and COGS models, the variance explained at level one amounts to $30 \%$ and $27 \%$, respectively, and at level two to $33 \%$ and $15 \%$. 
TABLE 3

What Drives Buying Group Membership?

\begin{tabular}{|c|c|c|c|c|}
\hline Variable & Estimate & & t-Value & \\
\hline Intercept & -3.563 & & $-6.82^{\star \star \star}$ & \\
\hline $\begin{array}{l}\text { Retailer's Motivation to Join a Buying Group } \\
\text { Economic Environment } \\
\text { GDP per capita } \\
\text { Consumer price index }\end{array}$ & $\begin{array}{r}.014 \\
-.013\end{array}$ & & $\begin{aligned} & 1.76^{\star} \\
-2.70^{\star \star \star} & -\end{aligned}$ & \\
\hline $\begin{array}{l}\text { Competitive Environment } \\
\text { Retail concentration } \\
\text { Home-market competitors in a group } \\
\text { Same-format competitors in a group }\end{array}$ & $\begin{array}{l}-.010 \\
4.041 \\
3.309\end{array}$ & & $\begin{array}{l}-2.59^{\star \star} \\
15.63^{\star \star \star} \\
10.60^{* \star *}\end{array}$ & \\
\hline $\begin{array}{l}\text { Retailer's Attractiveness to a Buying Group } \\
\text { Retailer size } \\
\text { Market position in home market } \\
\text { Importance of home market }\end{array}$ & $\begin{array}{l}.025 \\
.045 \\
.009\end{array}$ & & $\begin{array}{l}5.61^{\star * \star} \\
7.20^{\star * \star} \\
3.44^{\star * \star}\end{array}$ & \\
\hline $\begin{array}{l}-2 \text { log-likelihood } \\
\text { Likelihood ratio } \\
\text { Pseudo- } R^{2} \\
\text { Hit ratio }\end{array}$ & & $\begin{array}{c}1,168.30 \\
921.42 \\
(p<.0001) \\
.44 \\
90.1 \%\end{array}$ & & \\
\hline $\begin{array}{l}{ }^{*} p<.10 . \\
{ }^{* *} p<.05 . \\
\text { Notes: Two-sided tests of significance. }\end{array}$ & & & & \\
\hline notion that, on average, buying group membership & & Productivity & COGS & Sales \\
\hline In an additional step, we aim to obtain a first impression & $\begin{array}{l}\text { Number of groups } \\
\text { with beneficial effect }\end{array}$ & $58 \%$ & $67 \%$ & $58 \%$ \\
\hline Equation 1 by substituting the GroupMembership dummy & $\begin{array}{l}\text { Number of groups } \\
\text { with beneficial and } \\
\text { significant effect }\end{array}$ & $50 \%$ & $25 \%$ & $33 \%$ \\
\hline
\end{tabular}

representing membership to each individual buying group covered in our data. Formally,

$$
\text { (3) } \begin{aligned}
\text { Performance }_{\mathrm{t}, \mathrm{r}, \mathrm{g}} & =\pi_{0}+\sum_{\mathrm{i}=1}^{24} \alpha_{\mathrm{i}} \mathrm{BG}_{\mathrm{t}, \mathrm{g}} \\
& +\sum_{\mathrm{k}=1}^{2} \pi_{\mathrm{k}} \text { EconomicEnvironment }_{\mathrm{t}, \mathrm{r}} \\
& +\sum_{\ell=1}^{3} \pi_{2+\ell} \text { CompetitiveEnvironment }_{\mathrm{t}-1, \mathrm{r}} \\
& +\sum_{\mathrm{m}=1}^{4} \pi_{5+\mathrm{m}} \text { Investments }_{\mathrm{r}}+\pi_{10} \rho_{\mathrm{t}, \mathrm{r}}+\mathrm{e}_{\mathrm{r}}+\varepsilon_{\mathrm{t}, \mathrm{r}} .
\end{aligned}
$$

Comparing the $\alpha$ coefficients, which represent the effect of group membership on retailer performance for different buying groups, enables us to gain some initial insight in the heterogeneity of buying group effectiveness. We find that, indeed, not all buying groups are alike. We find a positive (significant) effect of group membership on retailer productivity and sales for, respectively, 58\% (50\%) and 58\% (33\%) of the buying groups in our sample. For $67 \%(25 \%)$ of the buying groups, we find a negative (significant) effect on retailers' COGS.

These findings imply that the hoped-for effects of buying group membership do not always materialize and that the performance of group members may depend on the composition of the buying group. In Study 2, we aim to extend this insight. In addition, even retailers within the same buying group may benefit differentially from their membership depending on their position within the group, an issue that we also explore in Study 2.

\section{Study 2}

\section{Overview}

To further explore how (1) the composition of the buying group and (2) the position of the retailer within the group contribute to retailer performance, we concentrate on the "treatment sample" and study the performance of the 63 retailers that were active in a buying group. To correct for the self-selection of retailers into groups, we use a two-step Heckit procedure. As before, we use a probit model to predict buying group membership (see Equation 1) using all observations of the treatment and control samples. Using the estimates from the probit model, we compute the inverse Mills ratio for GroupMember equal to $1(\lambda)$ and include it in the equation to test $\mathrm{H}_{1}-\mathrm{H}_{5}$. 
TABLE 4

Study 1: Do Buying Groups Impact Retailer Performance?

\begin{tabular}{|c|c|c|c|c|c|c|}
\hline \multirow[b]{2}{*}{ Variable } & \multicolumn{2}{|c|}{ Retailer Productivity } & \multicolumn{2}{|c|}{ COGS } & \multicolumn{2}{|c|}{ Sales } \\
\hline & Estimate & t-Value & Estimate & t-Value & Estimate & t-Value \\
\hline $\begin{array}{l}\text { Intercept } \\
\text { Group membership }\end{array}$ & $\begin{array}{l}.011 \\
.006\end{array}$ & $\begin{array}{l}.17 \\
3.09^{\star \star \star}\end{array}$ & $\begin{array}{r}-81.311 \\
-3.425\end{array}$ & $\begin{array}{l}-5.04 \\
-5.74^{\star \star \star}\end{array}$ & $\begin{array}{r}-177.050 \\
1.615\end{array}$ & $\begin{array}{c}-4.20 \\
1.80^{*}\end{array}$ \\
\hline $\begin{array}{l}\text { Control Variables } \\
\text { Economic Environment } \\
\text { GDP per capita } \\
\text { Consumer price index }\end{array}$ & $\begin{array}{l}.025 \\
.096\end{array}$ & $\begin{array}{r}3.70^{\star \star \star} \\
13.39^{\star \star \star}\end{array}$ & $\begin{array}{l}2.752 \\
9.188\end{array}$ & $\begin{array}{l}1.75^{\star} \\
5.47^{\star \star \star}\end{array}$ & $\begin{array}{r}14.639 \\
.105\end{array}$ & $\begin{array}{l}3.35^{\star \star \star} \\
5.01^{\star \star \star}\end{array}$ \\
\hline $\begin{array}{l}\text { Competitive Environment } \\
\text { Retail concentration } \\
\text { Home-market competitors in a group } \\
\text { Same-format competitors in a group }\end{array}$ & $\begin{array}{r}.008 \\
-.012 \\
-.002\end{array}$ & $\begin{array}{l}1.44 \\
-4.28^{\star \star \star} \\
-1.93^{\star \star}\end{array}$ & $\begin{array}{r}2.970 \\
-2.883 \\
.231\end{array}$ & $\begin{array}{c}2.64^{\star \star *} \\
-3.15^{\star \star *} \\
.39\end{array}$ & $\begin{array}{r}2.581 \\
-8.709 \\
-4.750\end{array}$ & $\begin{array}{c}1.81^{\star} \\
-4.14^{\star \star \star} \\
-3.04^{* \star *}\end{array}$ \\
\hline $\begin{array}{l}\text { Retailer Investments } \\
\text { EDI } \\
\text { RFID } \\
\text { Loyalty program } \\
\text { Online operations }\end{array}$ & $\begin{array}{r}.007 \\
.028 \\
.011 \\
-.027\end{array}$ & $\begin{array}{r}3.15^{\star \star \star} \\
12.50^{\star \star \star} \\
6.06^{\star \star \star} \\
-13.52^{\star \star \star}\end{array}$ & $\begin{array}{l}6.137 \\
7.755 \\
1.777 \\
2.100\end{array}$ & $\begin{array}{l}2.25^{\star \star} \\
2.64^{\star \star \star} \\
.90 \\
3.80^{\star \star \star}\end{array}$ & $\begin{array}{r}10.804 \\
10.770 \\
1.572 \\
1.448\end{array}$ & $\begin{array}{l}2.97^{\star \star \star} \\
2.88^{\star \star \star} \\
.52 \\
1.98^{\star \star}\end{array}$ \\
\hline $\begin{array}{l}\text { Endogeneity Correction } \\
\text { Control function } \rho\end{array}$ & -.010 & $-5.98^{\star \star \star}$ & -3.128 & $-5.98^{\star \star \star}$ & -5.588 & $-5.94^{\star \star \star}$ \\
\hline $\mathrm{N}$ & 1,6 & 692 & & & 1,6 & \\
\hline
\end{tabular}

\section{Model}

Formally, we estimate a three-level hierarchical structure to reflect that time observations are nested within retailers and that retailers are nested within buying groups:

(4) MemberPerf , $, \mathrm{r}, \mathrm{g}=\pi_{0}+\pi_{1}$ Scale $_{\mathrm{t}-1, \mathrm{~g}}$

$$
\begin{aligned}
& +\pi_{2} \text { SizeHetero }_{\mathrm{t}-1, \mathrm{~g}} \times \text { Scale }_{\mathrm{t}-1, \mathrm{~g}} \\
& +\pi_{3} \text { GeoScope }_{\mathrm{t}-1, \mathrm{~g}} \times \text { Scale }_{\mathrm{t}-1, \mathrm{~g}} \\
& +\pi_{4} \text { ProdScope }_{\mathrm{t}-1, \mathrm{~g}} \times \text { Scale }_{\mathrm{t}-1, \mathrm{~g}} \\
& +\pi_{5} \text { RelSize }_{\mathrm{t}-1, \mathrm{r}, \mathrm{g}} \times \text { Scale }_{\mathrm{t}-1, \mathrm{~g}} \\
& +\pi_{6} \text { GeoOverlap }_{\mathrm{t}-1, \mathrm{r}, \mathrm{g}} \times \text { Scale }_{\mathrm{t}-1, \mathrm{~g}} \\
& +\pi_{7} \text { ProdOverlap }_{\mathrm{t}-1, \mathrm{r}, \mathrm{g}} \times \text { Scale }_{\mathrm{t}-1, \mathrm{~g}} \\
& +\pi_{8} \text { SizeHetero }_{\mathrm{t}-1, \mathrm{~g}}+\pi_{9} \text { GeoScope }_{\mathrm{t}-1, \mathrm{~g}} \\
& +\pi_{10} \text { ProdScope }_{\mathrm{t}-1, \mathrm{~g}}+\pi_{11} \text { RelSize }_{\mathrm{t}-1, \mathrm{r}, \mathrm{g}} \\
& +\pi_{12} \text { GeoOverlap }_{\mathrm{t}-1, \mathrm{r}, \mathrm{g}}+\pi_{13} \text { ProdOverlap }_{\mathrm{t}-1, \mathrm{r}, \mathrm{g}} \\
& +\sum_{\mathrm{k}=1}^{2} \pi_{13+\mathrm{k}} \text { EconomicEnvironment }_{\mathrm{t}, \mathrm{r}} \\
& +\sum_{\ell=1}^{3} \pi_{15+\ell} \text { CompetitiveEnvironment }_{\mathrm{t}-1, \mathrm{r}} \\
& +\sum_{\mathrm{m}=1}^{4} \pi_{18+\mathrm{m}} \text { Investments }_{\mathrm{r}} \\
& +\sum_{\mathrm{m}=1}^{2} \pi_{22+\mathrm{m}} \text { BGCharacteristics }_{\mathrm{t}, \mathrm{g}}+\pi_{25} \lambda_{\mathrm{t}, \mathrm{r}}+\mathrm{r}_{\mathrm{r}, \mathrm{g}} \\
& +\mathrm{u}_{\mathrm{g}}+\varepsilon_{\mathrm{t}, \mathrm{r}, \mathrm{g}} .
\end{aligned}
$$

Equation 4 expresses retail member performance (MemberPerf) as a function of buying group scale (Scale) and group and member characteristics. As to the group characteristics, SizeHetero captures the diversity among the group members in terms of their size, and GeoScope and ProdScope represent the buying group's diversity of geographic and product markets served. With regard to member characteristics, RelSize captures the retailer's size relative to its buying group peers, and GeoOverlap and ProdOverlap are indicators of the market overlap-in terms of geographic and product markets-between a retailer and the rest of the group.

We include four blocks of control variables. As in Study 1 and Equation 1, we control for the economic climate and the competitive environment in which the retailer operates as well as the retailer's supplier- and customer-centered investments. We also control for two buying group characteristics: the group's number of members and its age. A larger number of group members may make it more difficult to align individual interests. Because efficient operations typically involve learning by doing, which requires time, buying groups may perform better with age, although older groups may run the risk of becoming trapped by inertia. All independent variables, with the exception of the dummy variables, are mean-centered.

The error term $\varepsilon_{\mathrm{t}, \mathrm{r}, \mathrm{g}}$ is normally distributed with zero mean and variance-covariance matrix $\sigma^{2}$. The random effects $r_{r, g}$ and $u_{g}$ are normally distributed over retailers and buying groups, respectively, with an expected value of 0 , $\operatorname{var}\left(\mathrm{r}_{\mathrm{r}, \mathrm{g}}\right)=\tau_{0}$, and $\operatorname{var}\left(\mathrm{u}_{\mathrm{g}}\right)=\tau_{00}$. As such, we allow for a random-coefficient specification across retailers across groups on the intercept. To favor model convergence and 
stable parameter estimates, only the intercepts are specified as random.

\section{Estimation Results}

Table 5 presents the results. ${ }^{9}$ For the productivity model, the multilevel model captures $55 \%$ of the level-one variation (i.e., the across-time, within-retailer variation), $14 \%$ of the level-two variation (i.e., the between-retailer, within-

${ }^{9} \mathrm{We}$ use one-sided tests for directional hypotheses and twosided tests for alternative hypotheses. Because we did not formulate hypotheses for the control variables and for the main effects of the buying group and retail member characteristics, their reported $p$-values are two-sided. buying group variation), and $51 \%$ of the level-three variation (i.e., the between-buying group variation). For the COGS and sales models, the variance explained at level one amounts to $42 \%$ and $51 \%$, respectively, at level two to $16 \%$ and $73 \%$, and at level three to $65 \%$ and $47 \%$. Moreover, the inclusion of the buying group and group member characteristics beyond the control variables and buying group scale significantly improves the variance explained in all three models $(p<.01)$. All variance inflation factors are well below ten (maximum variance inflation factor $=8.0$ ). Thus, multicollinearity is not likely to be a problem.

We find a positive effect of buying group scale on retailer productivity and sales and a negative effect on

TABLE 5

Study 2: Why Does Group Member Performance Vary?

\begin{tabular}{|c|c|c|c|c|c|c|}
\hline \multirow[b]{2}{*}{ Variable } & \multicolumn{2}{|c|}{ Retailer Productivity } & \multicolumn{2}{|c|}{ COGS } & \multicolumn{2}{|c|}{ Sales } \\
\hline & Estimate & $\mathrm{t}$-Value & Estimate & t-Value & Estimate & t-Value \\
\hline Intercept & .738 & $78.12^{\# \# \#}$ & 20.284 & $3.86 \# \#$ & 14.773 & 4.61\#\#\# \\
\hline Group scale & .014 & $4.56^{\star \star *}$ & -2.673 & $-1.98^{\star \star}$ & 6.107 & $5.67^{\star \star \star}$ \\
\hline \multicolumn{7}{|l|}{ Interactions with Group Characteristics } \\
\hline Scale $\times$ Size heterogeneity & -.005 & $\begin{array}{l}-2.88^{\star \star \star} \\
177^{\#}\end{array}$ & $\begin{array}{r}2.390 \\
-1142\end{array}$ & $\begin{array}{c}3.30^{\star \star \star} \\
-198 \# \#\end{array}$ & $\begin{array}{r}-2.445 \\
1740\end{array}$ & $\begin{array}{l}-1.52^{*} \\
4.32 \# \# \#\end{array}$ \\
\hline Scale $\times$ Geographic-market scope & .002 & $1.77^{\#}$ & -1.142 & $-1.98^{\# \#}$ & 1.740 & 4.32\#\#\# \\
\hline Scale $\times$ Product-market scope & -.011 & $-4.32^{\# \# \#}$ & 3.026 & $2.47 \# \#$ & -1.130 & -1.38 \\
\hline \multicolumn{7}{|l|}{ Interactions with Member Characteristics } \\
\hline Scale $\times$ Relative member size & .003 & $3.27^{\star * *}$ & 1.133 & $4.44^{\star \star \star}$ & 3.565 & $11.03^{\star \star \star}$ \\
\hline Scale $\times$ Geographic-market overlap & -.006 & $-3.23^{\star \star \star}$ & -.146 & -.21 & .001 & .00 \\
\hline Scale $\times$ Product-market overlap & -.001 & -.71 & .512 & $1.61^{*}$ & .190 & .29 \\
\hline \multicolumn{7}{|l|}{ Main Effects } \\
\hline Size heterogeneity & -.002 & -.61 & -17.232 & $-2.53^{\#}$ & 2.375 & 1.23 \\
\hline Geographic-market scope & -.014 & $-8.05 \# \#$ & 8.934 & 4.67\#\#\# & .610 & .89 \\
\hline Product-market scope & -.010 & $-2.21^{\# \#}$ & -1.865 & -.47 & -2.651 & $-1.67^{\#}$ \\
\hline Relative member size & .000 & .09 & 1.436 & .48 & 1.775 & $5.62 \# \# \#$ \\
\hline Geographic-market overlap & -.004 & $-3.38^{\# \# \#}$ & -.491 & -.57 & 1.224 & .59 \\
\hline Product-market overlap & .001 & .18 & -1.201 & -1.19 & -.478 & -.18 \\
\hline \multicolumn{7}{|l|}{$\begin{array}{l}\text { Control Variables } \\
\text { Economic Environment }\end{array}$} \\
\hline GDP per capita & .010 & .94 & .710 & .38 & .847 & .25 \\
\hline Consumer price index & .076 & $6.28^{\# \# \#}$ & 10.470 & $2.27 \# \#$ & 3.854 & .91 \\
\hline \multicolumn{7}{|l|}{ Competitive Environment } \\
\hline Retail concentration & .004 & .69 & 2.056 & 1.03 & -2.522 & $-1.85^{\#}$ \\
\hline Home-market competitors in a group & .001 & .15 & -3.054 & $-4.48^{\# \# \#}$ & -8.232 & $-4.80^{\# \# \#}$ \\
\hline Same-format competitors in a group & -.020 & $-4.06 \# \# \#$ & -9.233 & $-4.29 \# \# \#$ & 3.049 & $1.97 \# \#$ \\
\hline \multicolumn{7}{|l|}{ Retailer Investments } \\
\hline EDI & -.006 & -.66 & -2.329 & -.19 & 5.140 & $2.23 \# \#$ \\
\hline RFID & .025 & $2.57 \# \# \#$ & 1.340 & .36 & 7.421 & $3.12^{\# \# \#}$ \\
\hline Loyalty program & .014 & 1.53 & 1.530 & 1.63 & 2.351 & 1.07 \\
\hline Online operations & -.007 & $-3.51 \# \# \#$ & 1.591 & .91 & -.607 & -.90 \\
\hline \multicolumn{7}{|l|}{ Buying Group Characteristics } \\
\hline Number of members & .004 & 1.07 & -1.448 & -.43 & -5.783 & $-3.68 \# \# \#$ \\
\hline Buying group age & .002 & 1.00 & -.777 & -.60 & 1.142 & 1.59 \\
\hline \\
\hline Inverse Mills ratio $\lambda$ & -.006 & $-1.68^{\#}$ & -7.248 & $-4.77 \# \# \#$ & -4.852 & $-3.82 \# \# \#$ \\
\hline $\mathrm{N}$ & \multicolumn{2}{|c|}{727} & \multicolumn{2}{|c|}{424} & \multicolumn{2}{|c|}{727} \\
\hline
\end{tabular}

${ }^{*} p<.10$ (one-sided).

${ }^{\star \star} p<.05$ (one-sided).

${ }^{* * *} p<.01$ (one-sided)

$\# p<.10$ (two-sided).

$\# \#<.05$ (two-sided).

$\# \#$ \# $<.01$ (two-sided). 
COGS, as suggested in $\mathrm{H}_{1}$ (productivity: $\pi=.014, p<.01$; COGS: $\pi=-2.673, p<.05$; sales: $\pi=6.107, p<.01)$. Furthermore, we find that a buying group's size heterogeneity decreases the beneficial effect of group scale on its members' productivity, COGS, and sales (productivity: $\pi=-.005, p<$ .01 ; COGS: $\pi=2.390, p<.01$; sales: $\pi=-2.445, p<.10$ ), thereby corroborating $\mathrm{H}_{2}$. We find support for both $\mathrm{H}_{3 \mathrm{a}}$ and $\mathrm{H}_{3 b}$, albeit for different types of market scope. Whereas the moderating effect of geographic-market scope is positive for productivity and sales and negative for COGS (productivity: $\pi=.002, p<.10$; COGS: $\pi=-1.142, p<.05$; sales: $\pi=1.740, p<.01$ ), which corroborates $\mathrm{H}_{3 \mathrm{a}}$, product-market scope has the opposite effect (productivity: $\pi=-.011, p<$ .01 ; COGS: $\pi=3.026, p<.01$; sales: $\pi=-1.130, p>.10$ ), in support of $\mathrm{H}_{3 \mathrm{~b}}$. Thus, the wider the geographic-market scope of the group and the narrower its product-market scope, the larger the beneficial effect of the group's scale on its members' performance.

Turning to the position of a retailer within a buying group, we find that relative member size positively moderates the effect of buying group scale on retailer productivity $(\pi=.003, p<.01)$ and sales $(\pi=3.565, p<.01)$, in line with $\mathrm{H}_{4}$. Thus, larger retailers in the group benefit more from buying group scale than their smaller counterparts. Notably, the smaller retailers benefit more in terms of cost advantages $(\pi=1.133, p<.01)$. Thus, although large members benefit most from buying group scale in terms of productivity increases, this effect does not materialize through reduced COGS but rather through product-related advantages that lead to increased sales. As to the moderating effect of geographic-market overlap $\left(\mathrm{H}_{5}\right)$, we only find support in terms of retailer productivity. The larger a retailer's geographic-market overlap with the group, the smaller the effect of group scale on that retailer's productivity $(\pi=-.006$, $p<.01)$. The moderating effect of product-market overlap is in line with $\mathrm{H}_{5}$ for COGS $(\pi=.512, p<.10)$ but does not affect either retailer productivity or sales. The more group members overlap in their product-market portfolio, the less they can generate COGS benefits. Web Appendix W4 attests to the robustness of our results.

\section{Simple Slope Analyses}

To further diagnose the nature of the significant interactions, we used simple slope tests (Cohen et al. 2003, pp. 267-82). We calculate the slope and associated significance level of buying group scale for three levels of each moderator: low (two standard deviations below the mean), medium (at the mean), and high (two standard deviations above the mean). We find that buying group scale always (i.e., at low, medium, and high levels of all moderators) significantly increases retailer productivity and sales. In contrast, the effect of buying group scale on COGS becomes insignificant at times (i.e., at certain levels of some moderators). Notably, although reduced COGS is often cited as the number-one reason to join buying groups, our results suggest that these benefits are very sensitive to the buying group's composition and to the retailer's position within the group.

When group members are highly heterogeneous in terms of their size, buying group scale no longer signifi- cantly reduces COGS $\left(\beta_{\text {high }}=-.229, p>.10\right)$. Not only is it more difficult for these groups to strike a balance between the diverging preferences of their members, they may also have a more difficult time striking deals with large brand owners that may question the advantage of collaborating with smaller retailers riding on the coattails of the larger retailer(s) within the group. This suppresses the cost benefits of group scale. Nevertheless, as the results for productivity and sales show, retailers in such groups may still be able to benefit from improved access to product ranges from smaller suppliers (in the form of, e.g., own-brand ranges, regional products). In addition, group scale no longer reduces COGS when the group's geographic-market scope is low $\left(\beta_{\text {low }}=-.007, p>.10\right)$, presumably because a narrow scope limits the information exchange about price differences between group members. In contrast, the negative effect of group scale on COGS is nullified when the group's product-market scope is high $\left(\beta_{\text {high }}=.315, p>.10\right)$, suggesting that aggregation across different product markets is less beneficial because retailers' product range interests may diverge too much.

As to the retailer's position in the group, the effect of buying group scale on COGS becomes insignificant for relatively large group members $\left(\beta_{\text {high }}=.058, p>.10\right)$. In other words, whereas smaller members benefit more from a cost advantage, larger counterparts benefit through increased sales rather than reduced costs. ${ }^{10}$ Finally, group scale does not significantly reduce COGS when productmarket overlap is high $\left(\beta_{\text {high }}=-1.860, p>.10\right)$, because a higher degree of overlap with direct competitors erodes the unique competitive advantage offered by the group.

\section{What-If Simulations}

To further illustrate the economic meaning of our findings and increase their managerial relevance, we conduct a what-if analysis to examine whether, and when, bigger is better. Because buying group membership is in a continuous flux, it is important for retailers to evaluate how these dynamics may affect their performance. In particular, retailers are actively on the lookout to scale up by moving to larger-scale groups, in the belief that the increased scale will increase their productivity. In addition, buying groups are seeking to scale up in an attempt to improve their members' performance by attracting new members. But what happens to a retailer when it becomes a member of a larger group? Because the composition of the group (size heterogeneity and market scope) and the position of the retailer within the group (relative size and overlap) are almost certainly bound to change at the same time, it is not straightforward that increased scale will always translate into increased productivity.

10Perhaps the reason smaller retailers benefit primarily in terms of COGS is because they need the buying group to achieve the lowered costs that give them the flexibility to keep prices more competitive with larger competitors. Thus, it is more a matter of survival than enhanced profitability, because without the lowered COGS and competitive prices, there would be no sales to generate those profits. We thank an anonymous reviewer for this suggestion. 
To address this question, we compare the baseline productivity for an average retailer in an average group (i.e., the intercept as reported in Table 5 [73.8\%]) with the productivity the retailer would achieve in a larger group, ${ }^{11}$ which may or may not have changed in terms of composition. We consider the absolute percentage shift in retailer productivity, calculated with Equation 4, by increasing (decreasing) the variables involved with two standard deviations above (below) their grand mean, while holding the other variables fixed at their baseline level (i.e., grand mean for continuous variables, zero for dummy variables).

When a retailer scales up (because it joins a larger group or because the buying group attracts additional members) but the composition of the group and the retailer's position within the group remain unchanged, retailer productivity increases from $73.8 \%$ to $77.2 \%$. Still, as group scale increases are likely to go hand in hand with changes in group composition and will affect the position of the retailer within the group, we must assess the consequences of these changes as well. When a retailer becomes a member of a larger-scale group, it will be more productive when it (1) is relatively larger within the group (larger: $79 \%$ vs. smaller: $75 \%)$, (2) overlaps less with its fellow members in terms of geographic markets (less: $81 \%$ vs. more: $74 \%$ ), and when the group (3) is less diverse in terms of the size of its members (less: 79\% vs. more: 76\%), (4) operates fewer store formats (lower: $81 \%$ vs. higher: $73 \%$ ), and (5) is not overstretching its geographic scope (low: $79 \%$ vs. high: $75 \%$ ).

Two conclusions emerge from these simulations that could not be gauged otherwise. First, whether bigger is better depends on the composition of the group and the retailer's position within the group. Indeed, the effect of increased scale is sometimes severely attenuated, with the effect of group scale being most sensitive to the number of store formats operated by the group members and the extent of the retailer's overlap in geographic markets. Second, the impact of geographic-market scope is more complex than it might first appear. Although the moderating effect of geographic-market scope on retailer productivity is positive, the total net effect of geographic-market scope is negative (due to its strong negative main effect). This implies that, overall, operating in groups that cover a broad scope of countries is detrimental.

\section{Discussion}

Retail interest in aggregating scale through buying groups is on the rise, as retailers believe it can result in important performance gains. In response, buying groups are striving to select new members and increase their scale in an attempt to bolster their members' returns. But is bigger always better? We find that, on average, buying groups indeed generate scale advantages for their members: group scale increases members' productivity and sales while

${ }^{11}$ Groups such as Alidis/Agenor and IRTS qualify as averagescale groups, while AMS Sourcing and EMD qualify as largescale groups. decreasing COGS. Notably, although buying groups are often depicted as pure cost-reducing entities, scale advantages seem to be realized more consistently through the sales route, whereas cost advantages are much more sensitive to the composition of and fit with the group. Some groups allow for a smoother translation of aggregate scale into retailer performance, while some retailers are better at seizing the scale-based benefits than others. To draw up a profile of both buying groups and group members excelling at leveraging these scale advantages, we studied the moderating impact of the group's size heterogeneity and the relative size of members within the group on the one hand and the group's market scope and overlap with individual member operations on the other hand. We summarize our results in Table 6 and reflect on the theoretical and managerial implications next.

\section{Theoretical Implications}

Our findings add to the extant literature on horizontal alliances by demonstrating the different roles that partner diversity (or similarity) may play in buying groups compared with other horizontal alliances. Diversity measures used in the extant literature on horizontal alliances have not always distinguished different types. In the context of R\&D alliances, Sivadas and Dwyer (2000), for example, measure partner similarity in terms of complementarity in objectives and products and find a positive effect of similarity on new product development success. Bucklin and Sengupta (1993, p. 44) report a positive effect of partner similarity on the success of marketing alliances and recommend that firms "build relationship with those having roughly similar endowments in terms of resources, market positions, and competitive capabilities." Our findings, however, show that similarity in terms of resources (i.e., size) versus similarity in terms of market operations exert different effects. Moreover, we further qualify similarity in terms of market operations along a geographic- and product-market subdimension.

A key takeaway from our study is that different types of diversity may exert opposite effects on buying group success. Along the size dimension, a main finding from our study is that in buying groups, size heterogeneity hurts and larger members benefit more. This finding stands in sharp contrast to the extant literature on horizontal alliances. Whereas in marketing alliances, there seems to be no discernable difference in the returns earned by the smaller and larger partners (Das, Sen, and Sengupta 1998), in R\&D alliances the smaller partners ultimately benefit more (Das, Sen, and Sengupta 1998; Kalaignanam, Shankar, and Varadarajan 2007). In R\&D alliances, larger firms usually seek out smaller, innovative firms to access their technological know-how. These small innovative firms have relatively high bargaining power because of their unique intellectual property (e.g., patented technologies). As a result, in R\&D alliances, size heterogeneity often is beneficial and smaller firms may benefit more - a finding that may be idiosyncratic to $\mathrm{R} \& \mathrm{D}$ alliances and is the exact reverse of what we theorize and find in the context of buying groups. Along the market operations dimension, we find that the geographic-market scope of the buying group helps group 


\begin{abstract}
Variable
Group scale $\left(\mathrm{H}_{1}\right)$

Size heterogeneity $\left(\mathrm{H}_{2}\right)$

Geographic- market scope $\left(\mathrm{H}_{3 a-b}\right)$

Product-market scope $\left(\mathrm{H}_{3 a-b}\right)$
\end{abstract}

Relative member size $\left(\mathrm{H}_{4}\right)$

Geographic-market overlap $\left(\mathrm{H}_{5}\right)$ Product-market overlap $\left(\mathrm{H}_{5}\right)$

\section{Results}

On average, buying group scale increases retailer productivity and sales and decreases COGS.

The more the group members are heterogeneous in size, the smaller the productivity, COGS, and sales gains from group scale.

The beneficial (negative) effect of buying group scale on COGS is completely nullified when the group is very heterogeneous in terms of member size.

The larger the geographic-market scope of a buying group, the larger the productivity, COGS, and sales gains from group scale.

Still, with respect to productivity, this beneficial moderating effect is not sufficient to compensate for the negative main effect of geographic-market scope. Overall, productivity is lower when the buying group's geographic-market scope is very wide.

The beneficial (negative) effect of buying group scale on COGS disappears completely when the buying group's geographic-market scope is low.

The product-market scope of a buying group decreases the scale advantage for productivity and COGS but not for sales.

The beneficial (negative) effect of buying group scale on COGS disappears completely when the buying group's product-market scope is high.

Larger members obtain more productivity and sales benefits than their smaller counterparts, but lower COGS advantages.

The beneficial (negative) effect of buying group scale on COGS disappears completely for very large members.

A retailer's geographic-market overlap with fellow group members diminishes the effect of group scale on productivity, but not on COGS or sales.

A retailer's product-market overlap with fellow group members decreases the scale advantage for COGS but bears no consequences with respect to productivity or sales.

The beneficial (negative) effect of buying group scale on COGS disappears completely for retailers whose product-market overlap with fellow group members is high. members generate a scale advantage, whereas too much geographic overlap hurts them. In contrast, product-market scope hurts, whereas product-market overlap is inconsequential. These findings again illustrate the importance of distinguishing different types of diversity.

Combined, our findings hold two important theoretical implications. First, not all horizontal alliances are alike, and researchers should be careful in generalizing prior insights on horizontal alliances to buying groups. Second, different dimensions of partner diversity should not be aggregated because they may have opposite effects; teasing them apart provides important insights. Value creation through buying groups requires the simultaneous pursuit of partners with similar characteristics on certain dimensions and different characteristics on other dimensions.

\section{Managerial Implications}

Implication 1: Is riding the coattail harmful? When buying groups are on the lookout for new members, they should try to attract similarly sized retailers. In this same vein, retailers that want to join a buying group should prioritize groups that are made up of similarly sized firms.

Implication 2: Is it better to be David or Goliath? Larger retailers may behave more like the "alpha dogs" in the pack, managing to negotiate product ranges that serve their specific needs while using the threat of exit to ensure a (more than) fair share of the benefits. Relatively smaller players should be careful not to overestimate the scale advantage of joining a buying group because they may have to agree with the whims and wishes of their larger counterparts. Notably, whereas the relatively smaller retailers gain more from group scale through lower buy-in prices, the relatively larger retailers seem to win most in terms of increased sales.

Implication 3: Should birds of the same country flock together? Although geographic diversity allows for insight in price differentials across many countries, which can be used to negotiate lower buy-in prices, it also leads to higher coordination costs. Combined, the coordination costs of a very wide geographic-market scope seem to outweigh the price benefits. At the same time, retailers should avoid a high degree of geographic-market overlap with their group peers. From the viewpoint of the buying group, attracting a new member with a high degree of geographic-market overlap will hurt at least one and possibly several current members.

Implication 4: Should birds of the same format flock together? Because retail formats differ greatly in terms of product assortments and the consumer segments to which they cater (Kahn and McAlister 1997), agreeing on the product range to be sourced may be more difficult when the group covers many different retail formats. The members of Bigs, for example, display considerable variety in retail formats, with stores ranging from convenience outlets to hypermarkets. The complexity of meeting the often divergent requirements of the various members explains why trading is seriously limited to a range of approximately 400 standardized own-brand products (IGD 2006, p. 78). Although retailers should try to avoid groups that cover a broad scope 
of store formats, they should be less concerned about potential product-market overlap with other group members; their most important consideration is to keep the productmarket scope of the group at bay.

\section{Using the Estimated Model in Performance Audits}

Combined, our results allow retailers to evaluate how buying group membership might affect their performance and which groups might be better candidates to serve their needs. To illustrate this, we turn to the Coopernic group. In 2014, Coopernic members Colruyt, Rewe, Coop (Switzerland), and Conad announced their intention to form a new group, Core, including all existing members of Coopernic minus Leclerc, stating that Leclerc would be excluded due to "insurmountable differences concerning the future form and strategic focus of the group" (Planet Retail 2013). The question then arises: to what extent was this decision driven by emotional rather than economic motives, as it reduced aggregate scale with $33 \%$ ? To assess the impact of this move on the group members' productivity, we constructed a dashboard for each member using our results from Table 5. We find that, despite the substantial drop in group scale, the resulting productivity change was relatively moderate. For example, for Rewe, the largest member in the new Core group, productivity dropped from $78 \%$ to $77.3 \%$. For Colruyt, the smallest member, productivity even slightly increased from $74.3 \%$ to $74.6 \%$. Indeed, although group scale decreased, several other performance drivers changed in these members' advantage: the group's product-market scope decreased by $10 \%$ while the relative size of these members within the group increased (Colruyt: $+18 \%$; Rewe: $+23 \%$ ). At one point in time, however, the new Core group considered getting French retailer Système $U$ on board to compensate for the lost group scale, but the deal fell through. Still, this may not have been a great loss, as productivity would have barely improved (Colruyt: from $74.6 \%$ to $74.7 \%$; Rewe: from $77.3 \%$ to $77.6 \%$ ). The addition of Système U would not have allowed them to increase scale sufficiently (group scale would still be 16\% lower than the old Coopernic group), while the relative size of Rewe and Colruyt would have deteriorated at the same time.

\section{Limitations and Further Research}

This research represents the first inquiry into a complex phenomenon. As such, the study has several limitations that offer immediate avenues for further research. First, our study focuses on buying group scale, which reflects the buying group's potential to exert power. Whether that potential is realized is, in turn, captured by the moderators in our framework. Further research could focus on a buying group's actual buying volume, which is a more fine-grained measure of the group's bargaining power than its aggregate scale.

Second, what is the effect of buying groups on (larger and smaller) brand suppliers, store brand suppliers, and dual branders? Furthermore, does growing buying group participation lead to a supply-side spiral effect and stimulate concentration upstream? Are we seeing an "arms race" mentality, in which each wave of consolidation provokes another?

Third, buying groups have the potential to deliver lower retail prices for consumers. However, when multiple retailers consolidate their purchases, retailer ranges may converge, and consumer choice may be reduced. Further research could consider both pro- and anticompetitive effects of buying groups and investigate when one dominates the other. The mixture of possible effects on consumer welfare is currently the subject of much debate among antitrust authorities.

Finally, future studies could examine the generalizability of our findings to other horizontal alliances for which size is a determining factor. The multipartner alliances in the global airline industry are a case in point, in which alliance partners aim to benefit from positive externalities emanating from the size of their aggregate customer base. Another example is trade associations, in which firms unite to exchange information and stand stronger relative to industry or policy stakeholders.

\section{REFERENCES}

Ailawadi, Kusum L. (2001), “The Retail Power-Performance Conundrum: What Have We Learned?" Journal of Retailing, 77 (3), 299-318.

Betancourt, Roger and David Gautschi (1988), "The Economics of Retail Firms," Managerial and Decision Economics, 9 (2), 133-44.

Bucklin, Louis P. and Sanjit Sengupta (1993), "Organizing Successful Co-Marketing Alliances," Journal of Marketing, 57 (April), 32-46.

Chen, Rachel R. and Paolo Roma (2011), "Group Buying of Competing Retailers," Production and Operations Management, 20 (2), 181-97.

Cohen, Jacob, Patricia Cohen, Stephen G. West, and Leona S. Aiken (2003), Applied Multiple Regression/Correlation Analysis for the Behavioral Sciences. Mahwah, NJ: Lawrence Erlbaum Associates.

Corstjens, Marcel and Rajiv Lal (2012), "Retail Doesn't Cross Borders: Here's Why and What to Do About It," Harvard Business Review 90 (4), 104-111.

Cui, Anna and Gina O'Connor (2012), "Alliance Portfolio Resource Diversity and Firm Innovation," Journal of Marketing, 76 (July), 24-43.

Das, Somnath, Pradyot K. Sen, and Sanjit Sengupta (1998), "Impact of Strategic Alliances on Firm Valuation," Academy of Management Journal, 41 (1), 27-41.

Dawson, Mike and Annette C. Müller (2010), "Talk with European Retailer Alliance AMS," Lebensmittel Zeitung, (accessed April 29, 2015), [available at http://www.german-retail-blog. com/topic/past-blogs/talk-with-ams-sourcing-105].

Dobson, Paul W. (2002), "Retailer Buyer Power in European Markets: Lessons from Grocery Supply," working paper, Loughborough University Research Series.

_ (2011), "Putting Retail Competition on a Level Playing Field," Handelskraft, (May 30).

Dutta, Shantanu, Om Narasimhan, and Surendra Rajiv (1999), "Success in High Technology Markets: Is Marketing Capability Critical?" Marketing Science, 18 (4), 547-68. 
ESM (2012), "Fly-Buy Might," European Supermarket Magazine, (September/October), 58-61.

Gauri, Dinesh K. (2013), "Benchmarking Retail Productivity Considering Retail Pricing and Format Strategy," Journal of Retailing, 89 (1), 1-14.

_ , Gabor Pauler, and Minakshi Trivedi (2009), "Benchmarking Performance in Retail Chains: An Integrated Approach," Marketing Science, 28 (3), 502-515.

Ghisli, Flavia A., Marcos R. Lupe, and Jose A.G. da Silveira (2014), "Horizontal Alliances Among Independent and NonIntegrated Retailers: A Worldwide Analysis," International Journal of Business and Commerce, 3 (10), 21-50.

Golder, Peter and Gerard J. Tellis (1993), "Pioneer Advantage: Marketing Fact or Marketing Legend," Journal of Marketing Research, 30 (May), 158-70.

Gomes-Casseres, Benjamin (1994), "Group Versus Group: How Alliance Networks Compete," Harvard Business Review, 72 (4), 62-74.

Gourieroux, Christian, Alain Monfort, Eric Renault, and Alain Trognon (1987), "Generalized Residuals," Journal of Econometrics, 34 (1/2), 5-32.

Gulati, Ranjay (1999), "Network Location and Learning: The Influence of Network Resources and Firm Capabilities on Alliance Formation," Strategic Management Journal, 20 (5), 397-420.

Hu, Qiaohai (Joice), Leroy B. Schwarz, and Nelson A. Uhan (2012), "The Impact of Group Purchasing Organizations on Healthcare-Product Supply Chains," Manufacturing \& Service Operations Management, 14 (1), 7-23.

IGD (2006), European Grocery Buying Groups. Letchmore Heath, UK: IGD.

- (2012), European Grocery Buying Groups Presentation. Letchmore Heath, UK: IGD.

Inderst, Roman and Nicola Mazzarotto (2009), "Buyer Power in Distribution," in Issues in Competition Law and Policy (ABA Antitrust Section Handbook), Wayne D. Collins, ed. Chicago: American Bar Association, 1611-37.

Jayachandran, Satish, Javier Gimeno, and P. Rajan Varadarajan (1999), "Theory of Multimarket Competition: A Synthesis and Implications for Marketing Strategy," Journal of Marketing, 63 (July), 49-66.

Kahn, Barbara and Leigh McAlister (1997), The Grocery Revolution. Reading, MA: Addison-Wesley.

Kalaignanam, Kartik, Venkatesh Shankar, and Rajan Varadarajan (2007), "Asymmetric New Product Development Alliances: Win-Win or Win-Lose Partnerships?” Management Science, 53 (3), 357-74.

Kumar, Nirmalya, Lisa Scheer, and Jan-Benedict E.M. Steenkamp (1995), "The Effects of Perceived Interdependence on Dealer Attitudes," Journal of Marketing Research, 32 (August), 34856.

Lazzarini, Sergio G. (2007), "The Impact of Membership in Competing Alliance Constellations: Evidence on the Operational Performance of Global Airlines," Strategic Management Journal, 28 (4), 345-67.

Li, Stan Xi and Royston Greenwood (2004), "The Effect of Within-Industry Diversification on Firm Performance: Synergy Creation, Multi-Market Contact and Market Structuration," Strategic Management Journal, 25 (12), 1131-53.

Li, Xinxin (2012), "Group Buying, Buyer Heterogeneity, and Sellers' Bargaining Power," Decision Sciences, 43 (5), 761-83.

Luo, Xueming, Aric Rindfleisch, and David K. Tse (2007), "Working with Rivals: The Impact of Competitor Alliances on Financial Performance," Journal of Marketing Research, 44 (February), 73-83.
Majumdar, Adrian, Leslie Neubecker, Ugur Akgun, and Markus Baldauf (2007), "The Competitive Effects of Buyer Groups," Economic Discussion Paper, Office of Fair Trading.

Messinger, R. Paul and Chakravarthi Narasimhan (2001), "Has Power Shifted in the Grocery Channel?" Marketing Science, 14 (2), 189-223.

MinnesotaLife (2009), "Buying Power: How Consortiums are Changing the Benefits Landscape," Getting More out of Life, (accessed April 30, 2015), [available at http://www.lifebenefits. com/lb/pdfs/GetMore15.pdf].

Moore, Sheena and Keven Gray (2011), "GPOs and Buying Consortiums Must Be on the Radar for 2011-2012," Spend Matters Perspectives, (accessed April 30, 2015), [available at http:// spendmatters.com/research-library/perspectives/gpos-andbuying-consortiums-on-radar-for-2011-2012/].

Nollet, Jean and Martin Beaulieu (2005), "Should an Organisation Join a Purchasing Group?" Supply Chain Management, 10 (1), 11-17.

O'Shaughnessy, John (2014), Competitive Marketing: A Strategic Approach. New York: Routledge.

Oxley, Joanne E. and Rachelle Sampson (2004), "The Scope and Governance of International R\&D Alliances," Strategic Management Journal, 25 (8/9), 723-49.

Planet Retail (2006), "Auchan Leaves IRTS," (December 20).

— (2013), “The Week in View: 9-15 Sept," (September 16), (accessed May 6, 2015), [available at http://www1.planetretail. net/news-and-events/planet-retail/blogs/week-view-9-15-sept]. - (2014a), "Metro Group, Auchan Create a Buying Behemoth," (October 23), (accessed April 30, 2015), [available at http:// www.planetretail.net/NewsAndInsight/Article/91038].

_ (2014b), "War Makes for Odd Bedfellows," (September 16), (accessed April 30, 2015), [available at http://www.planetretail. net/NewsAndInsight/Article/90253].

Rindfleisch, Aric (2000), "Organizational Trust and Interfirm Cooperation: An Examination of Horizontal Versus Vertical Alliances," Marketing Letters, 11 (1), 81-95.

and Christine Moorman (2001), "The Acquisition of Information in New Product Alliances: A Strength of Ties Perspective," Journal of Marketing, 65 (April), 1-18.

Rowley, Tim J., Henrich R. Greve, Hayagreeva Rao, Joel A.C. Baum, and Andrew V. Shipilov (2005), "Time to Break Up: Social and Instrumental Antecedents of Firm Exits from Exchange Cliques," Academy of Management Journal, 48 (3), 499-520.

Schotanus, Fredo, Jan Telgen, and Luitzen de Boer (2008), "Unfair Allocation of Gains Under the Equal Price Allocation Method in Purchasing Groups," European Journal of Operational Research, 187 (1), 162-76.

-, , and (2010), "Critical Success Factors for Managing Purchasing Groups," Journal of Purchasing \& Supply Management, 16, 51-60.

Sivadas, Eugene and F. Robert Dwyer (2000), “An Examination of Organizational Factors Influencing New Product Success in Internal and Alliance-Based Processes," Journal of Marketing, 64 (January), 31-49.

Swaminathan, Vanitha and Christine Moorman (2009), "Marketing Alliances, Firm Networks, and Firm Value Creation," Journal of Marketing, 73 (September), 52-69.

Xiong, Guiyang and Sundar Bharadwaj (2011), "Social Capital of Young Technology Firms and Their IPO Values: The Complementary Role of Relevant Absorptive Capacity," Journal of Marketing, 75 (November), 87-104.

Yin, Xiaoli, Jianfeng Wu, and Wenpin Tsai (2012), "When Unconnected Others Connect: Does Degree of Brokerage Persist After the Formation of a Multipartner Alliance?" Organization Science, 23 (6), 1682-99. 


\title{
WEB APPENDIX
}

\section{United We Stand: The Impact of Buying Groups on Retailer Productivity}

\author{
Inge Geyskens, Katrijn Gielens, and Stefan Wuyts
}

\section{WEB APPENDIX W1}

\section{Estimation of Retailer Productivity}

We estimate the following stochastic frontier model on the data pooled over all retailers and years, using a one-stage maximum likelihood method:

$$
\begin{aligned}
& \ln \left(\text { Sales }_{\mathrm{t}, \mathrm{r}}\right)=\mu_{0}+\mu_{1} \ln \left(\text { Area }_{\mathrm{t}-1, \mathrm{r}}\right)+\mu_{2} \ln \left(\text { BigBox }_{\mathrm{t}-1, \mathrm{r}}\right)+\mu_{3} \ln \left(\text { PriceFighter }_{\mathrm{t}-1, \mathrm{r}}\right)+ \\
& \mu_{4} \ln \left(\text { Neighbor }_{\mathrm{t}-1, \mathrm{r}}\right)+\mu_{5} \ln \left(\text { Online }_{\mathrm{t}-1, \mathrm{r}}\right)+\mu_{6} \ln \left(\text { Services }_{\mathrm{t}-1, \mathrm{r}}\right)+\mu_{7} \ln \left(\text { Wholeale }_{\mathrm{t}-1, \mathrm{r}}\right)+ \\
& \mu_{8} \ln \left(\text { Countries }_{\mathrm{t}-1, \mathrm{r}}\right)+\mathrm{v}_{\mathrm{t}, \mathrm{r}}-\mathrm{u}_{\mathrm{t}, \mathrm{r}}
\end{aligned}
$$

The efficiency or productivity score for each retailer, in each year, can be obtained as Productivity ${ }_{t, r}=$

$\mathrm{e}^{-\mathrm{u}_{t, r}}$. This score is subsequently used as a dependent variable in our focal model (see Krasnikov, Jayachandran, and Kumar 2009 for a similar practice). The stochastic frontier estimation results are shown in Table A1. 
TABLE A1

\begin{tabular}{lcc}
\hline \hline Variable & Estimate & t-Value \\
\hline Intercept & 5.200 & $15.13^{\# \#}$ \\
Store selling area & .263 & $15.57^{\# \#}$ \\
Share of big box operations & .225 & $3.71^{\# \#}$ \\
Share of price fighter operations & .065 & $6.12^{\# \#}$ \\
Share of neighborhood operations & .086 & $6.66^{\# \#}$ \\
Share of online operations & 5.589 & $8.05^{\# \#}$ \\
Share of service operations & 3.796 & $2.19^{\#}$ \\
Share of wholesaling operations & .109 & $2.29^{\#}$ \\
Number of country operations & .636 & \\
\hline -2LL & 4,246 & \\
\hline$\#$ \# $p$.01 ${ }^{\#} p<.05$ (two-sided) & &
\end{tabular}

Note. The OLS residuals are negatively skewed (skewness statistic $=-2.6$; standard error $=.06$ ). Hence, there is evidence of technical efficiency in the data and it makes sense to estimate a stochastic frontier model.

\section{Reference}

Krasnikov, Alexander, Satish Jayachandran, and V. Kumar (2009), "The Impact of Customer Relationship Management Implementation on Cost and Profit Efficiencies: Evidence from the U.S. Commercial Banking Industry," Journal of Marketing, 73 (6), 61-76. 


\section{WEB APPENDIX W2}

Overview of Buying Groups

\begin{tabular}{|c|c|c|c|c|c|c|c|c|}
\hline & \multirow{2}{*}{ Founded } & \multirow{2}{*}{ Dissolved } & \multicolumn{3}{|c|}{ Sales (bil. Euro) } & \multicolumn{2}{|c|}{ \# of Members } & \multirow{2}{*}{ International } \\
\hline & & & Mean & Min & Max & Min & Max & \\
\hline Alidis/Agenor & 1997 & & 76.85 & 61.41 & 89.04 & 2 & 4 & Yes \\
\hline AMS Sourcing & 1987 & & 159.54 & 77.49 & 198.40 & 3 & 12 & Yes \\
\hline Bigs & 1991 & & 23.06 & 3.72 & 28.65 & 4 & 9 & Yes \\
\hline Bloc & 1991 & & 11.95 & 9.60 & 13.37 & 3 & 5 & Yes \\
\hline Coopernic & 2006 & & 115.16 & 98.96 & 129.87 & 5 & 5 & Yes \\
\hline EMD & 1989 & & 58.03 & 33.50 & 112.41 & 7 & 15 & Yes \\
\hline Eurogroup & 1988 & & 58.97 & 31.74 & 86.89 & 3 & 5 & Yes \\
\hline Eurolec & 2002 & 2006 & 34.11 & 33.02 & 35.76 & 2 & 2 & Yes \\
\hline Euromadi & 1993 & & 19.80 & 10.91 & 23.92 & 5 & 10 & No \\
\hline Europartners & 1995 & & 7.13 & 6.81 & 7.46 & 3 & 3 & Yes \\
\hline Fallesindkob & 1998 & 2005 & 6.38 & 3.80 & 7.67 & 2 & 2 & No \\
\hline Ifa Espanol & 1960 & & 33.77 & 3.54 & 64.27 & 3 & 8 & No \\
\hline Inex & 1992 & 2005 & 6.52 & 4.63 & 8.98 & 2 & 2 & No \\
\hline Intermedia & 1989 & 2010 & 23.60 & 3.18 & 61.46 & 3 & 4 & No \\
\hline IRTS & 2002 & 2006 & 79.39 & 75.04 & 85.53 & 2 & 2 & Yes \\
\hline Lucie & 1999 & 2006 & 39.42 & 32.01 & 45.28 & 2 & 2 & Yes \\
\hline Markant & 1991 & & 407.13 & 169.91 & 549.66 & 9 & 11 & No \\
\hline Mecades & 1996 & 2006 & 74.19 & 45.82 & 128.40 & 3 & 7 & No \\
\hline $\mathrm{Naf}$ & 1918 & & 26.09 & 21.23 & 30.48 & 4 & 6 & Yes \\
\hline Opera & 1999 & 2005 & 36.78 & 30.10 & 41.58 & 2 & 2 & No \\
\hline Rewe & 2005 & & 55.96 & 46.06 & 62.35 & 3 & 4 & No \\
\hline SED & 1994 & 2005 & 33.06 & 15.57 & 55.20 & 3 & 4 & Yes \\
\hline Superunie & 1956 & & 4.84 & .55 & 7.39 & 12 & 15 & No \\
\hline Unil KK & 1995 & & 10.46 & 2.09 & 19.25 & 2 & 2 & No \\
\hline
\end{tabular}




\section{WEB APPENDIX W3}

\section{Study 1: Descriptive Statistics and Correlations}

$\begin{array}{lllllllll}(1) & (2) & (3) & (4) & (5) & (6) & \text { (7) } & \text { (8) } & \text { (9) }\end{array}$

\begin{tabular}{|c|c|c|c|c|c|c|c|c|c|c|c|}
\hline (1) & Group membership & 1 & & & & & & & & & \\
\hline (2) & GDP per capita & .29 & 1 & & & & & & & & \\
\hline (3) & Consumer price index & .04 & .11 & 1 & & & & & & & \\
\hline (4) & Retail concentration & .28 & .68 & .18 & 1 & & & & & & \\
\hline (5) & Home-market competitors in a group & .51 & .59 & .08 & .54 & 1 & & & & & \\
\hline (6) & Same-format competitors in a group & .26 & .02 & .14 & .14 & .27 & 1 & & & & \\
\hline (7) & EDI & .06 & .14 & .01 & .15 & .16 & .14 & 1 & & & \\
\hline (8) & RFID & .18 & .17 & .03 & .14 & .19 & .15 & .51 & 1 & & \\
\hline (9) & Loyalty program & .23 & .17 & .01 & .17 & .17 & .14 & .22 & .33 & 1 & \\
\hline (10) & Online operations & .05 & .11 & .17 & .16 & .20 & .16 & .25 & .27 & .15 & 1 \\
\hline & Mean $^{\mathrm{a}}$ & $43.9 \%$ & 20,976 & 98.0 & 50.4 & .5 & .5 & $23.1 \%$ & $24.1 \%$ & $39.1 \%$ & $18.7 \%$ \\
\hline & Standard deviation & & 8,927 & 14.9 & 19.0 & .3 & .2 & & & & \\
\hline & Minimum & & 589 & 17.48 & .1 & 0 & 0 & & & & \\
\hline & Maximum & & 41,901 & 195.4 & 97.3 & 1.0 & 1.0 & & & & \\
\hline
\end{tabular}

${ }^{\mathrm{a}}$ For dummy variables, we report the frequency with which the event occurs. 


\section{WEB APPENDIX W3}

\section{Study 2: Descriptive Statistics and Correlations}

\begin{tabular}{|c|c|c|c|c|c|c|c|c|c|c|c|c|c|c|c|c|c|c|c|}
\hline & & (1) & $(2)$ & (3) & (4) & (5) & (6) & (7) & (8) & (9) & (10) & (11) & (12) & (13) & (14) & (15) & (16) & (17) & (18) \\
\hline (1) & Group scale (bil. Euro) & 1 & & & & & & & & & & & & & & & & & \\
\hline (2) & Size heterogeneity & -.56 & 1 & & & & & & & & & & & & & & & & \\
\hline (3) & Geo.-market scope & .61 & -.33 & 1 & & & & & & & & & & & & & & & \\
\hline (4) & Product-market scope & .62 & -.44 & .70 & 1 & & & & & & & & & & & & & & \\
\hline (5) & Relative member size & .06 & -.03 & .10 & .06 & 1 & & & & & & & & & & & & & \\
\hline (6) & Geo.-market overlap & -.12 & -.03 & -.16 & -.17 & .08 & 1 & & & & & & & & & & & & \\
\hline (7) & Product-market overlap & -.24 & .12 & -.15 & -.08 & .08 & .12 & 1 & & & & & & & & & & & \\
\hline (8) & GDP per capita & -.05 & -.09 & .04 & -.02 & .01 & .26 & .07 & 1 & & & & & & & & & & \\
\hline (9) & Consumer price index & .25 & -.22 & .24 & .20 & -.06 & .06 & -.07 & .21 & 1 & & & & & & & & & \\
\hline (10) & Retail concentration & -.05 & .00 & .09 & .02 & -.02 & .21 & .22 & .45 & .18 & 1 & & & & & & & & \\
\hline (11) & Home-market compet. & .06 & .02 & .06 & .03 & .02 & .19 & -.05 & .42 & .21 & .16 & 1 & & & & & & & \\
\hline (12) & Same-format compet. & .07 & -.07 & .09 & .05 & -.10 & -.03 & -.03 & .01 & .24 & .06 & .16 & 1 & & & & & & \\
\hline (13) & EDI & .09 & .13 & .27 & .20 & .24 & .18 & .02 & .11 & .01 & .09 & .16 & -.04 & 1 & & & & & \\
\hline (14) & RFID & .04 & .03 & .25 & .09 & .29 & .13 & .05 & -.03 & -.01 & .11 & .10 & -.02 & .47 & 1 & & & & \\
\hline (15) & Loyalty program & -.08 & .07 & .11 & .01 & .10 & .06 & .28 & .20 & -.06 & .18 & -.12 & -.07 & .27 & .26 & 1 & & & \\
\hline (16) & Online operations & .00 & .00 & .13 & .10 & .01 & .11 & .23 & -.15 & .24 & .05 & .04 & .04 & .22 & .21 & .02 & 1 & & \\
\hline (17) & Number of members & .75 & -.77 & .55 & .63 & .14 & -.14 & -.32 & -.12 & .25 & -.15 & -.02 & .05 & -.09 & -.07 & -.25 & -.03 & 1 & \\
\hline \multirow[t]{5}{*}{ (18) } & Buying group age & .02 & -.26 & -.23 & -.02 & -.05 & -.22 & -.01 & -.08 & .25 & .03 & -.06 & .05 & -.29 & -.25 & -.23 & .04 & .31 & 1 \\
\hline & Mean $^{\mathrm{a}}$ & 7.7 & .4 & 19.7 & 12.7 & 3.6 & .7 & .8 & 23.7 & 98.6 & 57.1 & .6 & .6 & $32 \%$ & $25 \%$ & $50 \%$ & $7 \%$ & 6.3 & 17.6 \\
\hline & Standard deviation & 6.9 & .2 & 14.3 & 5.3 & 8.4 & .3 & .3 & 6.0 & 8.3 & 16.6 & .2 & .1 & & & & & 3.6 & 15.5 \\
\hline & Minimum & .6 & .1 & 1.0 & 2.0 & 0 & 0 & .1 & 8.8 & 61.4 & 8.3 & 0 & .1 & & & & & 1.0 & 0 \\
\hline & Maximum & 198.4 & 1.0 & 49.0 & 23.0 & 13.1 & 1.0 & 1.0 & 41.9 & 117.2 & 97.3 & 1.0 & 1.0 & & & & & 15.0 & 84.0 \\
\hline
\end{tabular}

${ }^{\mathrm{a}}$ For dummy variables, we report the frequency with which the event occurs. 


\section{WEB APPENDIX W4}

\section{Robustness Checks}

\section{Are the results robust to alternate input-output measures?}

We re-estimated Equation (4) twice, using two alternative input-output measures: (1) a simple productivity ratio, viz. a simple sales—-store-space ratio and (2) an operating profitability measure, viz. earnings before interest and taxes (EBIT). As was the case for COGS, EBIT data were only available for a subset $(\mathrm{N}=55)$ of the retailers in our performance sample. Moreover, in several instances, the EBIT data were not available for every year in the observation window. In total, 452 retailer-year observations were available for EBIT.

Our focal productivity measure and these two alternative input-output measures move in the same direction: the Spearman rank-order correlations being .60 $(p<.01)$ and $.30(p<.01)$ for the simple sales - store-space ratio and the EBIT measure, respectively. The results of estimating Equation (4) are always consistent in sign and, with two exceptions, also in significance for these alternative measures, which further attests to the robustness of our findings. When a simple sales - store-space ratio is used, the moderating effect of size heterogeneity turns insignificant $(p=.32)$. When an EBIT measure is used, the moderating effect of geographic-market scope becomes insignificant $(p=.12)$.

\section{Are the results robust to different sample compositions?}

We checked to what extent our results are sensitive to the presence of retailers who were not in the top 100 during the entire duration of our 15-year observation window, because they were either too small at the start of the window (34 retailers) or because they became too small or went out of business before the end (30 retailers). To that extent, we reran our model twice, using only information on the retailers that were top 100 players (1) in the last year and (2) the first year of our observation window. When the data are only based on retailers who made the top 100 in the last year of our window, the non-significant 
moderator effect of product-market overlap becomes negative and significant in the productivity model, as predicted by $\mathrm{H}_{5}$. The moderating effect of geographic-market scope effect is no longer significant in the COGS model when we restrict ourselves to the last year of our window $(p=.16)$ nor in the sales model when we restrict ourselves to the first year of our window $(p=.19)$, although the signs remain the same. Otherwise, all effects are similar in sign and significance. Hence, our results are robust across these different samples.

\section{Are the results robust when the interaction between group scale and group age is included?}

To explore whether the effect of buying group scale changes as groups mature, we added an interaction effect between group scale and group age to Equation 4. In a dyadic context, relationship age has been shown to capture similar developmental information as relationship life cycle stages (Palmatier et al. 2013). Likewise, buying group age could proxy for common understandings between the members of a buying group, the idea being that coordination improves with time. We indeed find that both the positive

effect of group scale on retailer productivity $(p<.10)$ and the negative effect of group scale on COGS $(p$ $<.01)$ become significantly more pronounced in older groups. Most importantly, all other effects remain similar in sign and significance. These results further attest to the robustness of our findings.

\section{Reference}

Palmatier, Robert W., Mark B. Houston, Rajiv P. Dant, and Dhruv Grewal (2013), "Relationship Velocity: Toward a Theory of Relationship Dynamics," Journal of Marketing, 77 (1), 13-30. 
Copyright of Journal of Marketing is the property of American Marketing Association and its content may not be copied or emailed to multiple sites or posted to a listserv without the copyright holder's express written permission. However, users may print, download, or email articles for individual use. 